\title{
41. FORMATION TEMPERATURES AND PRESSURES IN A SEDIMENTED RIFT HYDROTHERMAL SYSTEM: 10 MONTHS OF CORK OBSERVATIONS, HOLES 857D AND 858G ${ }^{1}$
}

\author{
E.E. Davis ${ }^{2}$ and K. Becker ${ }^{3}$
}

\begin{abstract}
Four sites were drilled in Middle Valley, northern Juan de Fuca Ridge, during Ocean Drilling Program Leg 139 in order to characterize four hydrologically distinct parts of this hydrothermally active, sediment-filled mid-ocean rift. Fluid recharge was documented along a rift-bounding normal fault at Site 855 , where vertical displacement has exposed permeable basalt in the foot-wall block. A large, mature hydrothermal sulfide deposit was sampled at Site 856 . Holes at Site 857 penetrated a highly altered and permeable hydrothermal "reservoir" zone beneath the sediment seal. A zone of focused discharge above a buried basement edifice was studied with a transect of holes at Site 858. Single deep reentry holes were established at Sites 857 and 858 ; these were sealed and instrumented after drilling with recently developed "CORKs" to prevent the exchange of ocean and formation water, and to allow formation temperatures and pressures to be monitored for up to three years.

Data from both borehole observatory installations were recovered roughly three weeks after the drilling leg using a manned submersible; data from Site 858 were recovered roughly ten months after installation with a remotely operated vehicle. Pressures in the holes early in the monitoring period were dominated by the effect of cool water present in the holes after drilling. Immediately after the CORKs were installed, large negative differential pressures were recorded: $-0.24 \mathrm{MPa}$ in $\mathrm{Hole} 858 \mathrm{G}$ and $-1.12 \mathrm{MPa}$ in Hole 857D. Conditions in Hole 857D appear to have been recovering normally during the 3-week period of recording, although the recovery was slow; only half of the initial perturbation to pressure had decayed after three weeks. At Site 858, flow of seawater into the sediment section and basement via a nearby unsuccessfully plugged exploratory hole continued to dominate the pressure and temperatures recorded in the sealed hole for the duration of the 1-year recording period. Undisturbed formation pressures were estimated from the observed initial shut-in pressures by correcting for the difference between the density of the cool water in the holes at the time of sealing and the density of water at the estimated local undisturbed thermal state. Fluid pressure in basement at Site 857 is very close to hydrostatic, whereas fluid in basement at Site 858 is estimated to be locally overpressured by possibly up to $0.45 \mathrm{MPa}$. This pressure is available to drive flow vertically through the sediment section lying above the basement edifice at this discharge site, and laterally through permeable sediment layers that surround the edifice. If pressure losses to flow in the discharge zone are sufficiently small, a simple hydrologic model demonstrates that fluid pressures could exceed lithostatic at depths as great as $60-70 \mathrm{~m}$. Brecciation in the sediment section is observed in cores from depths as great as $50 \mathrm{~m}$, thus indicating that this situation may occasionally occur. Also present in the CORK data are short-period pressure and temperature variations that are often correlated. Tidal-frequency variations in Hole $857 \mathrm{D}$ provide constraints on the average modulus $\left(3.5 \times 10^{10} \mathrm{~Pa}\right)$ and permeability (less than $4.5 \times 10^{-14} \mathrm{~m}^{2}$ ) of the sediment. Several transient events were observed in both the temperature and pressure records from Hole $858 \mathrm{G}$. These are inferred to be associated with fracturing events nearby, or with slumping within and partial restriction of flow down Hole 858F.
\end{abstract}

\section{BACKGROUND}

Despite the lack of topographically induced head, hydrologic regimes in sediments and igneous crustal rocks beneath the seafloor are very active. Driving forces for fluid flow derive from rapid sediment accumulation and associated consolidation in sedimentary basins, tectonic thickening and associated consolidation in subduction zone accretionary prisms, and thermal buoyancy in ridge-crest and ridge-flank settings. The consequences of fluid flow within the igneous and sedimentary parts of the oceanic crust and between the crust and the water column are profound. Fluid circulation in the igneous crust dominates the heat budget at ridge crests, to the extent that at some spreading rates it may not be possible for magma chambers to be maintained in steady state (e.g., Lister, 1983). High-temperature hydrothermal fluids are extremely effective at dissolving and transporting large quantities of sulfur and base metals from the igneous crust to the seafloor and forming large polymetallic sulfide deposits (Hekinian et al., 1980; Koski et al., 1984; Rona et al., 1986; Davis et al., 1987). Long-term circulation of lower temperature crustal fluids is believed to be responsible for the

${ }^{1}$ Mottl, M.J., Davis, E.E., Fisher, A.T., and Slack, J.F. (Eds.), 1994. Proc, ODP. Sci. Results, 139: College Station, TX (Ocean Drilling Program).

${ }^{2}$ Pacific Geoscience Centre, Geological Survey of Canada, P.O. Box 6000 , Sidney, B.C. V8L 4B2, Canada.

${ }^{3}$ Rosenstiel School of Marine and Atmospheric Science, University of Miami, 4600 Rickenbacker Causeway, Miami, FL 33149, U.S.A. general alteration and mechanical consolidation of the upper igneous crust (Alt et al., 1986; Houtz and Ewing, 1976; Purdy, 1987). Fluid pressures generated in subduction zone accretionary prisms modify the mechanical behavior of the deforming sediment section (e.g., Bangs et al., 1990; Davis et al., 1983; Moore, Mascle, et al., 1988), and the resultant fluid flow may be responsible for methane migration, the formation of methane hydrates, and for diagenetic changes in the sediments (Hyndman and Davis, 1992).

Despite the major consequences of fluid flow in marine sediments and igneous oceanic crust, relatively few observations have been made that bear directly on relevant parameters such as the magnitude of the driving forces, the rates of flow, and the nature of permeability; for the most part, fluid flow regimes have been inferred from estimated thermal regimes. Some quantitative constraints have been placed on the distribution and rates of flow through the seafloor by direct observation (e.g., Carson et al., 1990; Little et al., 1987; Schultz et al., 1992) and by measurements made remotely or on cored material, (e.g., Schultheiss and McPhail, 1986; Langseth et al., 1988; Davis et al., 1991; Davis, Chapman, et al., 1992; Mottl and Wheat, in press). Constraints on the physical and chemical nature of crustal fluid flux at depth have been gained through measurements and sampling in several seafloor boreholes drilled by the Deep Sea Drilling Program (DSDP) and the Ocean Drilling Program (ODP). Logging and downhole experiments have provided valuable information (Anderson and Zoback, 1982; Anderson et al., 1985; Becker, 1990; Becker et al., 1983, 1989; Worthington et al., 1989), and significant progress has been made toward 


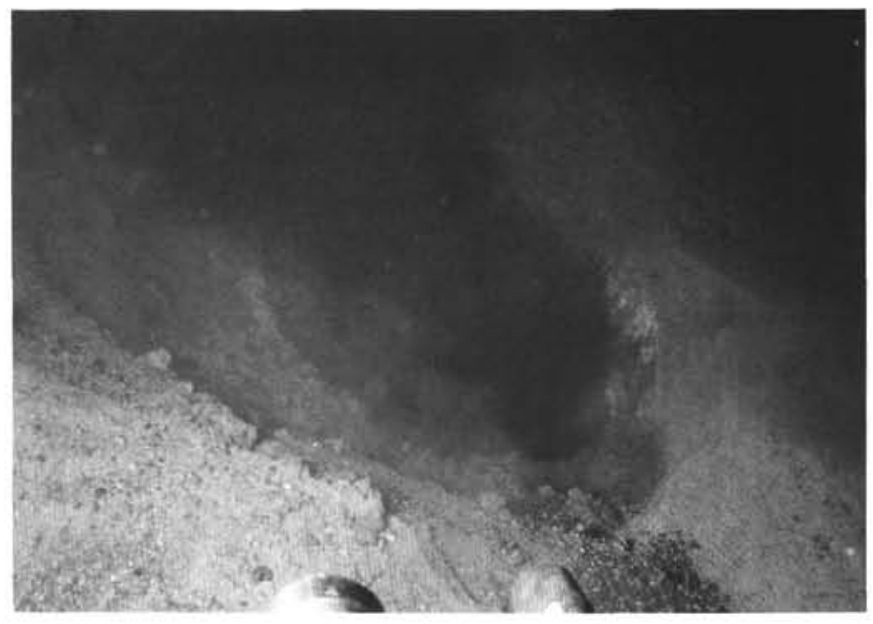

Figure 1. Photograph of Hole 858B, taken from Alvin, drilled to a depth of 30 mbsf in the Dead Dog vent field. The hole was visited 3 weeks after drilling, at which time strong uphole fluid flow had been established. Particulate-laden fluid can be seen discharging from the hole at the seafloor. Unfortunately, no temperature data nor fluid samples were collected.

developing instrumentation that will allow oceanic boreholes to be used as "natural laboratories" for long-term "observatory" experiments (e.g., Duennebier, Stephen, Gettrust, et al., 1987; Menard, Natland, Jordan, Orcutt, et al., 1987; Ingle, Suyehiro, von Breymann, et al., 1990; Judge et al., 1989; H. Kinoshita et al., unpubl. data, 1990; Taylor et al., 1989). Unfortunately, large differential pressures are often created between warm formation fluids and the cool seawater circulated during drilling, and downhole flow that severely disturbs the natural thermal, chemi$\mathrm{cal}$, and hydrologic regime is often stimulated (Anderson and Zoback, 1982; Erickson et al., 1975; Hyndman et al., 1976; Becker et al., 1983, 1984, 1989; Gable et al., 1992; Morin et al., 1992). In the case of one shallow hole drilled during Leg 139 (Hole 858B), discharge was initiated, and a new hydrothermal vent was created (Fig. 1). Clearly, these major perturbations severely compromise the quality of many downhole measurements and samples, both over short and long periods of time.

The instrumentation outlined here, developed through a cooperative project between the authors, T. Pettigrew (Ocean Drilling Program), B. Carson (Lehigh University), and R. Macdonald (Pacific Geoscience Centre), and referred to as the circulation obviation retrofit kit (CORK), represents a further advance toward a true "observatory" capability. It provides a means by which formation-fluid flow through seafloor boreholes can be stopped to minimize the thermal and chemical effects on the formation from drilling-induced disturbances, and by which the in situ thermal and hydrological conditions can be monitored and fluids can be sampled long after holes are drilled and after drilling disturbances have dissipated. The CORKs deployed during Leg 139 include: (1) a hydrologic seal that is compatible with existing ODP reentry cones and slightly modified ODP casing hangers (Figs. 2 and 3), (2) a data logger having a recording capacity for up to 2-3 yr of monitoring, (3) a downhole string of 10 thermistors, (4) a pressure sensor situated below the reentry cone seal, and (5) a means by which fluids can pass from the formation, through the seal, and be sampled by a submersible or a remotely operated vehicle (ROV) (Figs. 2 and 3). Instruments constructed for deployment in holes drilled during ODP Leg 146 into the Cascadia accretionary prism include orthogonal pairs of relatively low resolution (10 microradians) tilt sensors.

The seal comprises two parts. The outer part, deployed and recovered by the drilling ship, provides a seal to the standard $30 \mathrm{~cm}\left(11^{3 / 4} / 4\right.$-in. inside diameter) casing string, and also serves as a landing collar for the inner part, the data logger and its 9-cm (3.5 in.) outer-diameter,

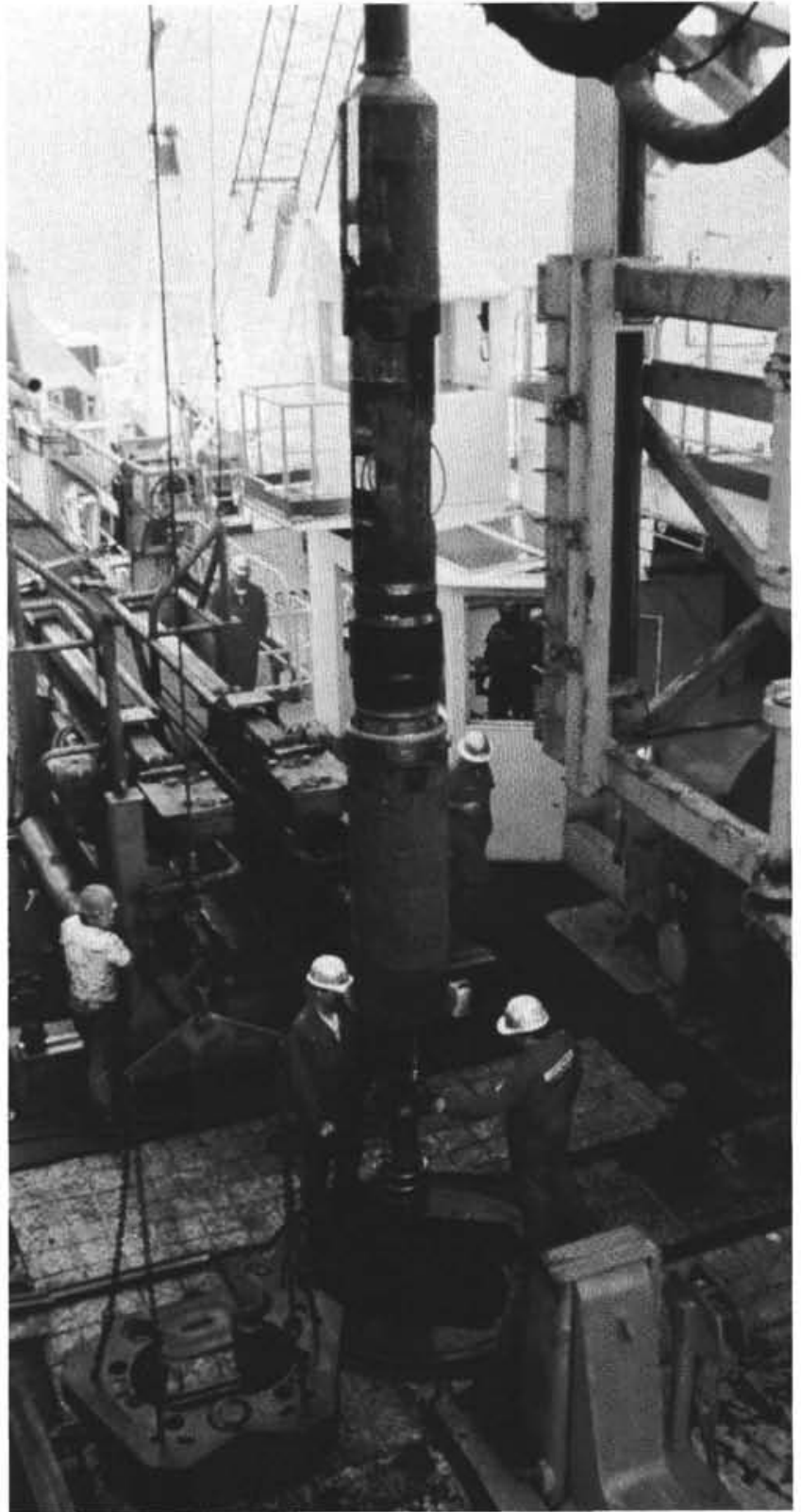

Figure 2. CORK unit assembled for deployment at Site 857. The packers that seal inside the $11^{3 / 4}$-in. casing are visible just above the level of the rig floor.

6-cm ( $2.5 \mathrm{in}$.) inner-diameter pressure case, which can be recovered by the drillship or by an ROV. All seals and latches are designed to be capable of containing either positive or negative differential pressures of up to $10 \mathrm{MPa}$. The data from the instrument are recovered via an electrical connection that can be mated by submersible, ROV, or wireline (Figs. 3 and 4). A more complete technical description of the instrumentation is given in Davis, Becker, et al. (1992).

\section{DEPLOYMENTS IN MIDDLE VALLEY DURING LEG 139}

Sedimented ridges and ridge flanks provide an ideal environment for hydrologic borehole seal experiments. Seafloor sediment, and in particular the glacially derived clay-rich sediment covering the northern Juan de Fuca Ridge and ridge flank, is known to be of extremely low permeability relative to the rock of the upper igneous crust that 


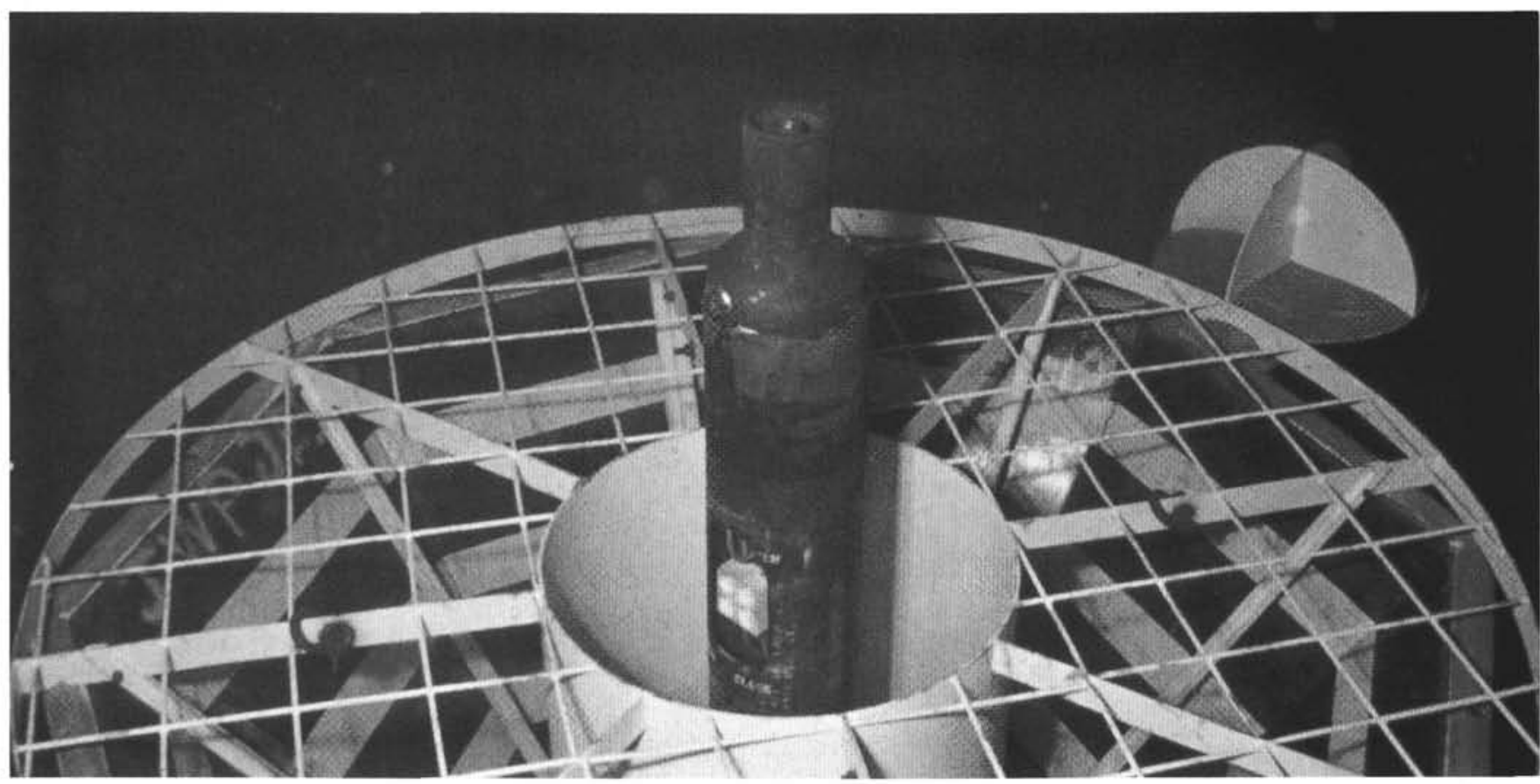

Figure 3. Photograph taken from Alvin showing the reentry cone at Hole $858 \mathrm{G}$ in Middle Valley, northern Juan de Fuca Ridge, fitted with an instrumented CORK borehole seal. The top of the data logger, which contains a coaxial underwater-mateable electrical connector can be seen just inside the top of the CORK housing. Hydraulic ports for bleeding pressure and unlatching the CORK seal are seen on the CORK housing at the level of the submersible landing grid that covers the reentry cone throat. The fluid sampling port and control valve are out of sight on the opposite side.

lies beneath (e.g., Becker et al., this volume; Fisher et al, this volume). Thus, cased boreholes through the sediment section can provide simple hydrologic connections to permeable formation below, and make possible the determination of local absolute pressures and lateral pressure differentials. Coupled with estimates and determinations of the regional and local thermal, tectonic, and hydrologic structure of the sediment and upper igneous crust, the hydrogeologic regimes in these ridge-crest and flank environments can be estimated with new confidence (e.g., Bessler et al., this volume).

During Leg 139, a total of 22 holes were drilled at four sites in the sedimented rift valley, Middle Valley, of the northern Juan de Fuca Ridge, to investigate four distinct parts of the submarine hydrothermal system active there (Davis, Mottl, Fisher, et al., 1992). Site 855 is situated in an area of fluid recharge along the normal-fault scarp that bounds the valley to the east. Drilling at Site 856 sampled a large polymetallic sulfide deposit created by hydrothermal fluid discharge that is no longer active. Holes at Site 857 were drilled into a hydrothermal "reservoir" zone where high-temperature fluids were suspected to reside in the upper igneous crust beneath a complete sediment seal. Holes at Site 858 were located in and immediately adjacent to a hydrothermal vent field. The holes nearest the center of the field (Holes 858B, -D, -F, and -G) penetrate an active upflow zone, where hydrothermal fluids ascend through the locally attenuated section of sediment above a buried basement edifice and vent at the seafloor. CORKs were installed at the latter two of these sites, in reentry Holes $857 \mathrm{D}$ and $858 \mathrm{G}$

\section{Instrumented Reentry Holes}

Hole $857 \mathrm{D}$ penetrates a 470-m-thick section of turbidites, and on into a sequence of interbedded sills and indurated sediments to a total depth of 936 meters below the seafloor (mbsf) (Shipboard Scientific Party, 1992a; Fig. 5). The hole was cased well into this sequence, down to a depth of 580 mbsf. Reliable temperature measurements were obtained only down to a depth of $80 \mathrm{mbsf}$. The thermal structure at greater depths has been estimated by Villinger et al. (this volume) and Davis and Wang (this volume), who have extrapolated the shallow temperature measurements using estimated thermal conductivity profiles. They both conclude that temperatures increase with depth to roughly $280^{\circ} \mathrm{C}$ at the top of the sill complex. The estimated temperature at the depth of the bottom of the sensor string in Hole 857D is roughly $190^{\circ} \mathrm{C}$. Two zones of extremely high permeability were intersected by this hole below the casing (Becker et al., this volume); the combination of high permeability and the large differential pressure between the cold-hole and warm-formation hydrostats of roughly 1 $\mathrm{MPa}$ (see discussion below) stimulated downhole flow at a rate of over 10,000 liters/min (Shipboard Scientific Party, 1992a). Sealing the hole at the seafloor was clearly necessary to prevent major thermal and chemical disturbances to the formation, and to permit in-situ temperatures and pressures to be measured directly. The hole was drilled to a much greater depth than anticipated; as a result, the $300-\mathrm{m}$-long thermistor chain used occupies less than one-third of the total hole depth, and the bottom of the fluid sampling tube is well above the bottom of the casing (Fig. 5). The initial choice of thermistor-chain lengths had been guided by the anticipated depths of drilling, the thermal gradients in the area, and the temperature limit imposed by the insulation used for the thermistor chain construction of $270^{\circ} \mathrm{C}$. A thermistor chain of $900-\mathrm{m}$ length has been constructed for this hole for deployment at a future time, with the goal of determining the thermal structure of the permeable sill complex, where heat transport is believed to be dominated by hydrothermal circulation.

Hole $858 \mathrm{G}$ is located within the "Dead Dog" vent field, roughly $1.6 \mathrm{~km}$ north of Hole 857D, and was drilled to a total depth of 433 mbsf (Shipboard Scientific Party, 1992b; Fig. 5B). Casing was set to a depth of $269 \mathrm{~m}$, about $11 \mathrm{~m}$ into basement. The thermal structure here is known to be dominated by hydrothermal upflow. Temperatures measured during Leg 139 increased rapidly in the upper 25-30 mbsf up to values close to the maximum temperature of nearby vents. The formation below $30-50 \mathrm{mbsf}$ is inferred to be roughly isothermal at about $280^{\circ} \mathrm{C}$. The basement section at this site comprises extrusive 


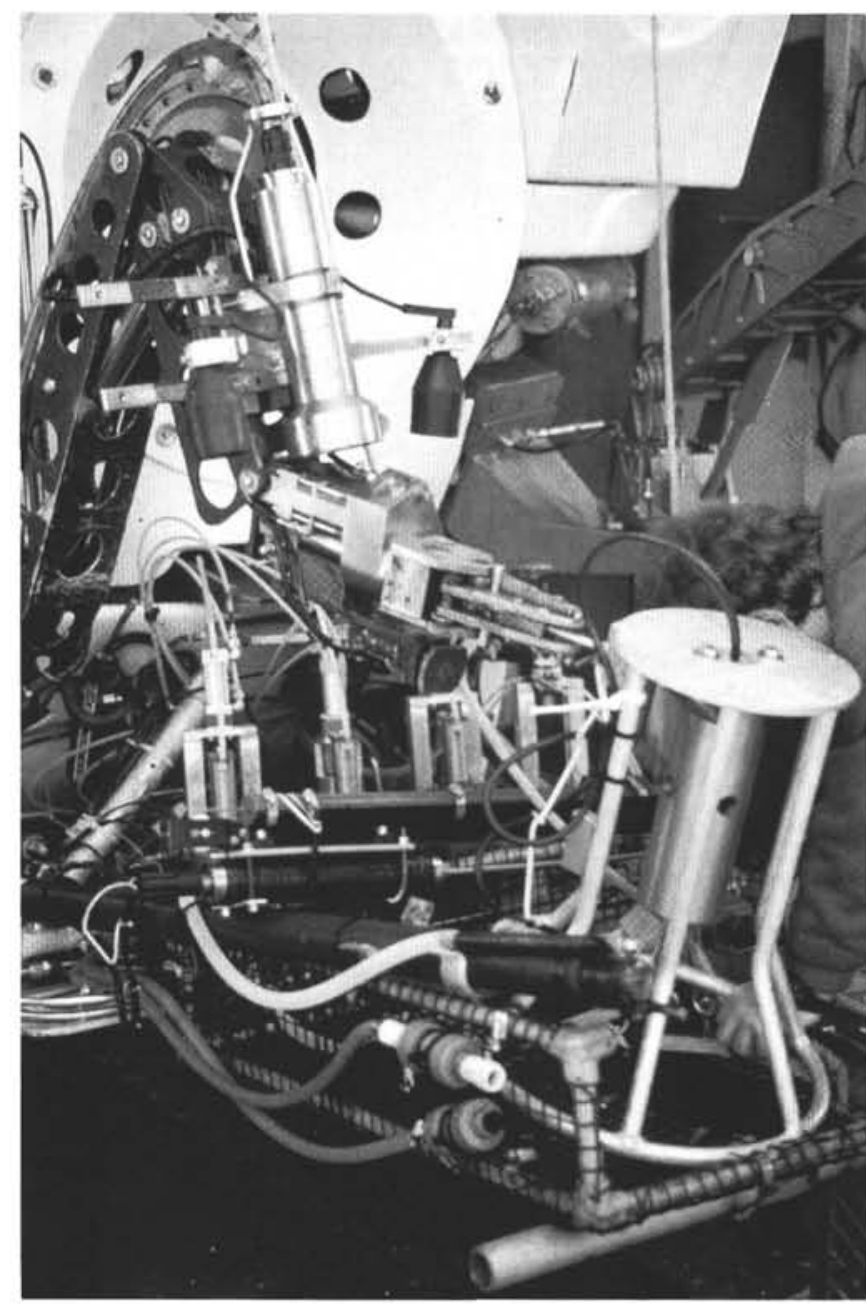

Figure 4. "Top-hat" self-aligning underwater mateable connector for CORK data logger communications, mounted for use on Alvin.

basalt which is permeable, although not to the extent of the basement sill complex at Site 857 (Becker et al., this volume). Downhole fluid flow into basement in Hole $858 \mathrm{G}$ was indicated by the nature of the temperature profile measured after deepening of the hole into basement below the casing. The sediment section was inferred to be permeable as well; downhole flow into the sediment section was inferred from the perturbation in Hole $858 \mathrm{G}$ caused by flow into the section via the nearby exploratory Hole $858 \mathrm{~F}$ (Shipboard Scientific Party, 1992b). The 385-m-long thermistor chain and fluid sampling tube installed in Hole $858 \mathrm{G}$ reaches well below the cased section of the hole; all thermistors of the chain should be within the isothermally hot part of the formation (Fig. 5).

\section{Exploratory Holes}

Single-bit exploratory holes were drilled near both reentry holes to determine the depth to which 16-in. casing could be washed in and the depth to which $11^{3 / 4}$-in. casing was required. Hole $857 \mathrm{C}$ is located $50 \mathrm{~m}$ to the south of Hole 857D and was drilled to a depth of $568 \mathrm{mbsf}$, roughly $100 \mathrm{~m}$ deeper in the section than the depth at which the first sill was encountered. Hole $858 \mathrm{~F}$ is located just $10 \mathrm{~m}$ to the north of Hole $858 \mathrm{G}$ and was drilled to a depth of $297 \mathrm{mbsf}$, roughly $40 \mathrm{~m}$ into igneous basement (Fig. 5). The extreme proximity of the exploratory and reentry holes at Site 858 was felt to be logistically necessary because of the anticipated large geologic variability in the vent field. To reduce the chance that flow into or out of the formation would take place in the exploratory holes, an attempt was made to backfill portions of each with cement (Davis, Becker, et al., 1992; Shipboard Scientific Party, 1992a, 1992b). Judging from the results of temperature logs and from the initial 2 months of CORK data, it appears that the attempt to backfill Hole $858 \mathrm{~F}$ was unsuccessful. Temperatures and the pressure measured in the neighboring cased and sealed Hole $858 \mathrm{G}$ appear to have been dominated by the effects of flow of seawater down Hole $858 \mathrm{~F}$ both at the time of drilling and throughout the period of recording (see discussion below).

\section{SITE VISITS AND DATA RECOVERY OPERATIONS}

Holes $858 \mathrm{G}$ and $857 \mathrm{D}$ were visited during a deep-submersible research vessel Alvin diving program on 24 September 1991, 15.5 and 21.5 days after the Leg 139 CORK installations were completed, respectively. Temperatures at each of the ten thermistors down the chains, temperatures inside the pressure cases, borehole pressure, and values of high-stability reference resistors were recorded at 10-min intervals during this first recording period. After data were downloaded, the recording interval in each instrument was reset to one hour to allow additional data to be recorded for a period of $2 \mathrm{yr}$. Hydraulic connections were also completed and differential pressures across the seals were measured directly with an analog gauge. No fluids could be recovered from either hole, however, because of the large negative differential pressures present.

A second visit to Site 858 was made on 13 October with the objective of installing a plug in the troublesome exploratory Hole $858 \mathrm{~F}$. The 2 -m-diameter conical plug was fabricated from $0.5-\mathrm{cm}$ thick steel and deployed in the configuration shown in Figure 6. Unfortunately, the flotation used for deployment was not carefully balanced against the weight of the plug and ballast chain, and the drop weight could not be released. This made the plug extremely difficult to maneuver with the submersible, and it could not be repositioned after it landed somewhat off-center in the hole. As a result, there was a gap of about $20 \mathrm{~cm}$ between the plug skirt and the seafloor along a $20^{\circ}$ segment of the circumference of the plug. That the seal was ineffective was clear from the lack of a differential pressure measured across the plug through the valved sampling port (Fig. 6), and from the temperatures and pressure recorded in the sealed Hole $858 \mathrm{G}$, which showed no signs of change at the time of plug placement (see discussion below).

A third visit to Site 858 was made on 3 July 1992, during a successful test program of a deep-ocean ROV developed and operated by the Canadian Departments of Fisheries and Oceans and Energy, Mines, and Resources. Data were successfully recovered at the sea surface via the fiber-optic cable linking the ship and the ROV.

Unfortunately, limited time and minor operational problems precluded data recovery at Hole $857 \mathrm{D}$ with the ROV. This hole was visited during Leg 146 in an attempt to recover the data logger and replace the short and malfunctioning thermistor chain with a new chain $900 \mathrm{~m}$ long. This operation was spoiled by bad weather and excessive heave; the upper CORK body above the fluid sampling port access windows (Figs. 2 and 3 ) was torn off, and the integrity of the CORK seal may have been compromised. Inspection with the drillstring video camera showed that the data logger and lower CORK body are still intact, but damage to the electrical connector and the data logger could not be assessed. An attempt will be made to download data, and possibly to recover and replace the complete logger and sensor string assembly in 1993. 

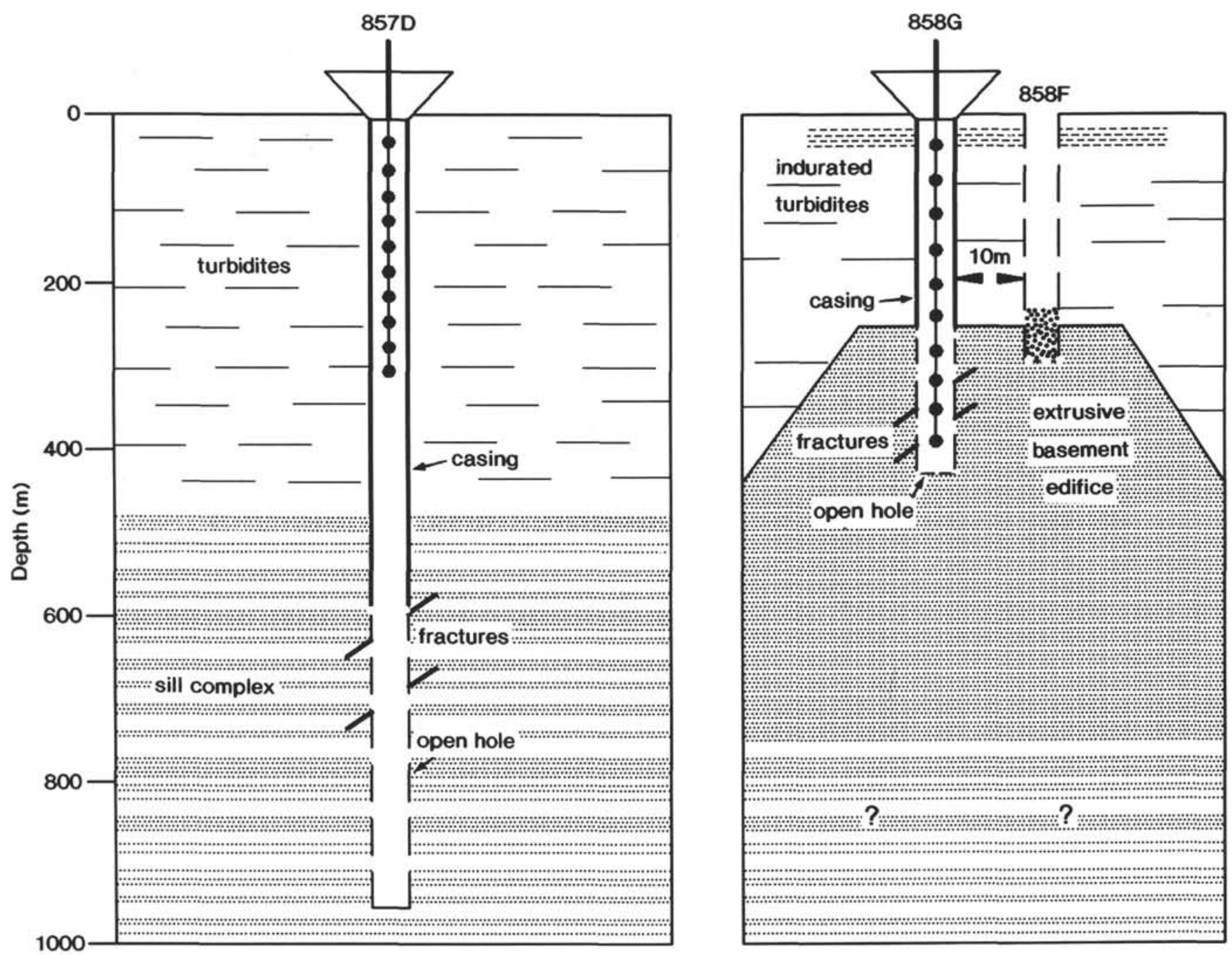

\section{$1.6 \mathrm{~km}$}

Figure 5. Schematic diagrams showing the general lithology penetrated by the cased and open sections of Hole 857D and Holes 858F and 858G, and the location of thermistors (points) hanging below the CORK seals. Thermistors are spaced at even intervals of $30 \mathrm{~m}$ below the seafloor in Hole 857D, and of 40 m in Hole $858 \mathrm{G}$ (with the exception of thermistor 10 which was moved up to $385 \mathrm{mbsf}$ ).

\section{RESULTS}

\section{Sensitivity and Errors}

Recorded borehole total pressure values should be accurate to within about $0.1 \%$ and repeatable to within $0.01 \%$ of the total pressure, or roughly $2.5 \mathrm{kPa}$ (nominally $25 \mathrm{~cm}$ of hydrostatic head). Errors in sensitivity over the ranges of pressures observed in the holes are insignificant, as are the limits of the digital resolution provided by the 24-bit data (less than $1 \mathrm{~mm}$ of head).

In addition to the CORK data, seafloor pressures are also used in the discussion below. Short-term seafloor pressure variations have been estimated from the locally determined phase and amplitude of tidal harmonics (A. Douglas, Institute of Ocean Sciences, pers. comm., 1992), and verified by comparison of these estimates to pressures recorded with a seafloor gauge deployed in August 1992 in Cascadia Basin, roughly $90 \mathrm{~km}$ southeast of the Middle Valley drilling sites (Fig. 7). Agreement between the estimated and recorded tidal pressure signal is good, although not perfect. Mismatch in amplitude is typically less than $1 \mathrm{kPa}$, and there is a minor lag in the estimated tidal signal of a few minutes. To eliminate the errors associated with estimating the local seafloor tide, future CORK instruments will be outfitted with a seafloor pressure gauge.

To avoid the inaccuracy of intergauge calibrations, the absolute levels of seafloor pressure have been adjusted (by a few tens of $\mathrm{kPa}$ ) according to the differential pressure measured at the time of the first Alvin dive to Holes $857 \mathrm{D}$ and $858 \mathrm{G}(552 \mathrm{kPa}$ in $857 \mathrm{D}$ and $345 \mathrm{kPa}$ in 858G; Figs. 8 and 9). Pressures recorded immediately before latching the CORK seals were not used as seafloor reference pressures because of the presence of strong downhole flow and associated pressure offsets (see discussion below).

In contrast to the highly accurate pressure data, the temperature data are compromised by seawater leakage into the epoxy-filled thermistor capsules, which occurred despite careful preparation of the Teflon capsules and wiring. Data are noisy at times, and absolute temperatures are probably erroneously high, especially at the low-temperature end of the range. It is most likely that there is a seawater electrical leakage path that parallels the thermistors (the resistances of which vary inversely with temperature). An attempt has been made to correct for this, using the in-situ "calibration" temperatures early in the history of recording. Temperatures given in figures are uncor- 


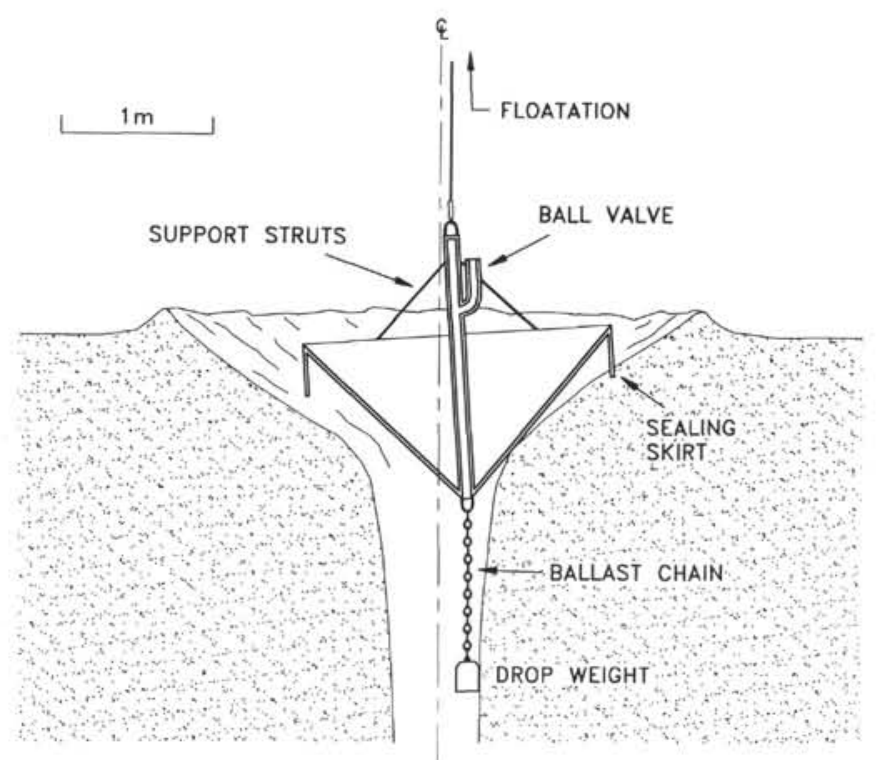

Figure 6. Cross-sectional schematic view of the plug placed in exploratory Hole $858 \mathrm{~F}$.

rected, however, and based only on the standard calibrations of the thermistors. Based on offsets during the time the strings were being lowered to the seafloor, the leakage is suspected to be roughly a few hundred $\mathrm{kOhms}$. The error imposed by this level of leakage would be several tens of Kelvin at seafloor temperature $\left(2^{\circ} \mathrm{C}\right)$, but would diminish to $15 \mathrm{~K}$ at $50^{\circ} \mathrm{C}, 5 \mathrm{~K}$ at $100^{\circ} \mathrm{C}, 2 \mathrm{~K}$ at $200^{\circ} \mathrm{C}$, and less at higher temperatures. These errors are large compared to the digital resolution provided by the instrumentation, which varies somewhat over the full temperature range but is less than $0.1 \mathrm{~K}$ on average. In thermistor strings built subsequently, capsules have been redesigned to reduce the potential for leakage. Compliant tapered stoppers are used to pass the thermistor wires into the Teflon thermistor cavities, which are backfilled with high-temperature silicon grease. We have no explanation for the large noise and offsets, often correlated from thermistor to thermistor, seen in the records of the deeper thermistors in both holes (see Figs. 8-10 below). Laboratory tests have demonstrated that the thermistors are insensitive to pressure, and that interchannel crosstalk in the data logger is negligible.

Clock times are logged with each data record. On the basis of time checks done at the times of data recovery, errors in time are insignificant, totaling only a few tens of seconds in the case of the 10-month recording period at Hole $858 \mathrm{G}$. Times used for processing and in all plots in this paper have been transformed to hours elapsed since the beginning of 1991 (Greenwich Meridian).

\section{First 3 Weeks of Data}

To better understand the data presented here and the discussions that follow, it is helpful to consider an idealized hole-sealing experiment in a borehole that penetrates a sediment seal overlying a basement formation sufficiently permeable to permit an initial downhole flow. Until the hole is sealed, fluid pressures in the borehole filled by cold seawater would be greater than fluid pressures in the hot formation, and the zone invaded by the downhole flow would be extensively cooled. Upon the installation of a seafloor seal, a pressure gauge below the seal should register a drop in pressure very nearly equal in magnitude to the differential between the cold hole and hot formation at the deepest permeable section penetrated by the hole. The borehole pressure should fall to this level with a time constant governed by the volume of water in the hole and the average permeability of the formation. With the downhole flow stopped, the invaded zone should begin a slow process of thermal recovery, and as tem-

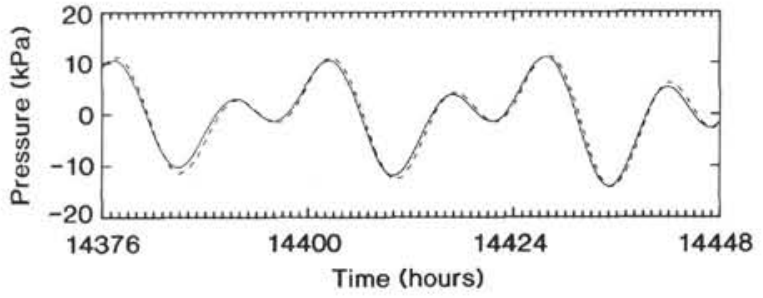

Figure 7. Three-day record of observed seafloor (solid) and estimated (dashed) tidal pressure variations. Time ticks are given hourly and labeled daily in hours since the beginning of 1991. Observations were made during a 3-week period in August and September 1992, at a seafloor gauge deployed at $47^{\circ} 44.9^{\prime} \mathrm{N}$, $127^{\circ} 46.9^{\prime} \mathrm{W}$, roughly $100 \mathrm{~km}$ southeast of the drill sites. The estimated tidal record is based on a prediction provided by A. Douglas (Institute of Ocean Sciences, pers. comm., 1992); an amplitude factor of 1.14 has been applied to the predicted tide to obtain the best fit to the observed signal for the 3 -week recording period. This adjusted estimate has then been used as the seafloor pressure reference signal for the CORK observational period.

peratures in the invaded zone warm toward geothermal values, the negative pressure differential sensed at the CORK should decrease in magnitude. Thus, the long-term temperature and pressure records should both show slow, smooth rises toward undisturbed formation values, with a time constant defined thermally according to the volume of rock originally invaded by downhole flow. To summarize much of the following interpretation, the 3-week records from Hole 857D follow this ideal scenario very nicely, but the $1 \mathrm{yr}$ of data from Hole $858 \mathrm{G}$ are much more complex and must be interpreted in terms of hydrologic contamination via the exploratory hole and/or vigorous hydrologic activity in the formation.

Pressures recorded during the first three weeks in Holes 857D and $858 \mathrm{G}$ are shown in Figures 8 and 9. Pressures rose rapidly as the instruments were lowered to the seafloor during deployment, but in neither hole did they reach the local seafloor hydrostatic level. The discrepancies ( $90 \mathrm{kPa}$ in Hole $857 \mathrm{D}$ and $70 \mathrm{kPa}$ in Hole $858 \mathrm{G}$ ) are believed to be the result of the method of deployment, which required that the hole be entered with a leading section of two drill collars assembled beneath the CORKs. With these "stingers" in and partially blocking the holes, but with the CORKs not yet seated in the reentry cones, the measured pressures were reduced below hydrostatic values by the resistance to the draw-down in the open holes, which continued actively until the instants the CORKs were seated in the reentry cones.

Immediately after the CORKs were seated, pressures in both holes fell to levels considerably below hydrostatic as anticipated. The post"shut-in" pressure was $-1120 \mathrm{kPa}$ in Hole $857 \mathrm{D}$, virtually the same as that measured below the drill-string packer during Leg 139 (Becker et al., this volume), and $-240 \mathrm{kPa}$ in Hole $858 \mathrm{G}$. As discussed below, we believe that all of the negative differential pressure was caused by the cold column of seawater occupying the holes at the time of shutin, and that there is no true formation underpressure at either site.

Subsequent histories in the two holes differ. The pressure in Hole $857 \mathrm{D}$ (Fig. 8) shows signs of what we interpret to be "normal" recovery towards original formation conditions. The long-term increase in pressure is probably associated with thermal recovery of the hole and surrounding formation. Although of poor quality, the CORK temperature data do show an unambiguous warming trend (with the exception of the uppermost thermistor) throughout the 3 -week recording period. With the same qualification about the quality of the data, temperatures near those estimated for the undisturbed formation (Villinger et al., this volume; Davis and Wang, this volume) are reached towards the end of the recording period at the deepest two thermistors.

In contrast, the pressure in Hole $858 \mathrm{G}$ became increasingly negative during the same period (Fig. 9). Although the direction of the trend is opposite, the cause may have been the same: changing temperature in the hole and in the formation immediately surrounding the hole. In this case, however, the change would not have been caused 

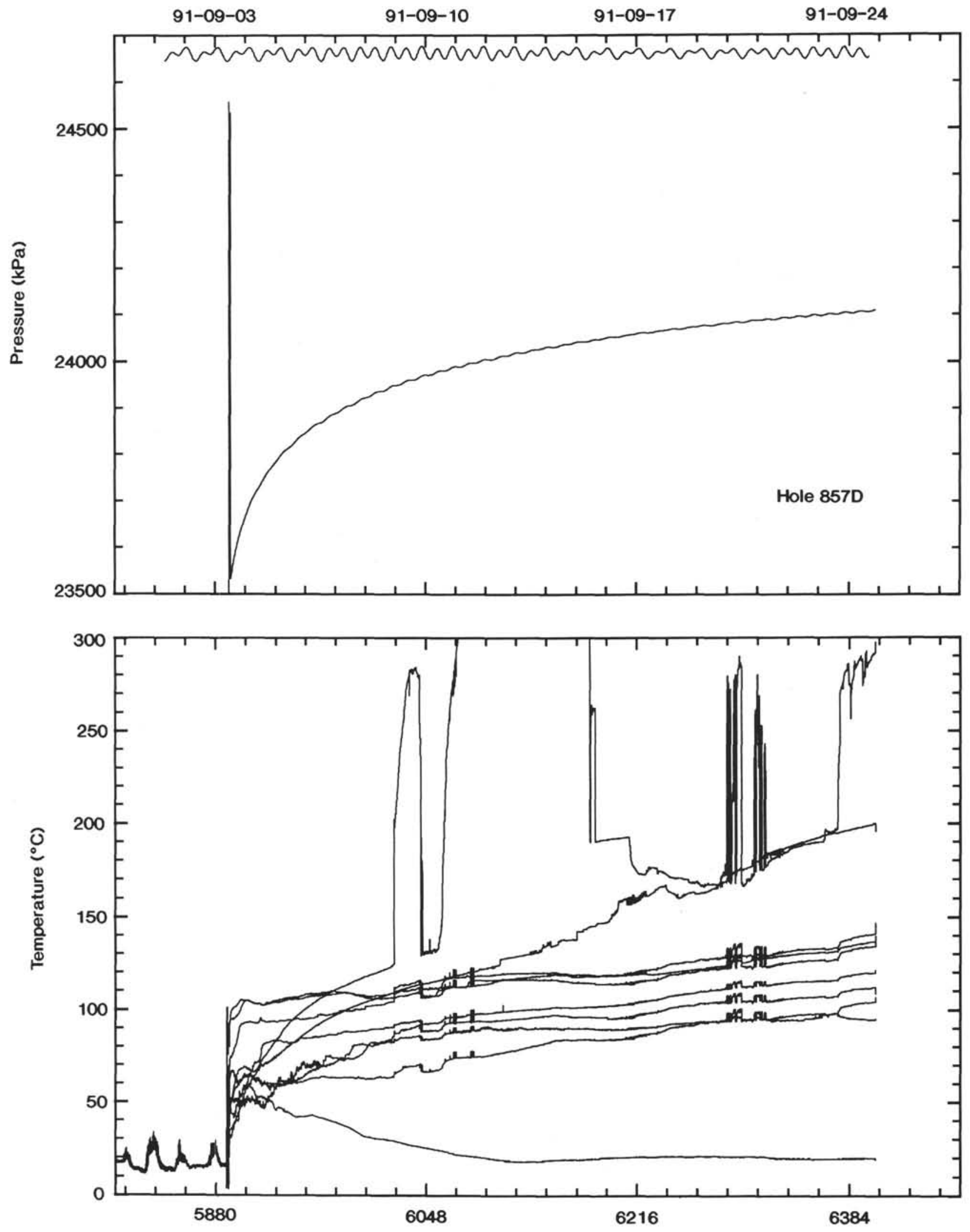

Time (hours)

Figure 8. Borehole pressure and temperatures recorded during the initial observation period in Hole 857D. An estimated seafloor tidal signal (upper line in pressure plot) is also shown for reference (see Fig. 7). Time ticks are given daily and labeled weekly. Times in this and all other figures are given as hours elapsed since the beginning of 1991 (Greenwich Meridian). 

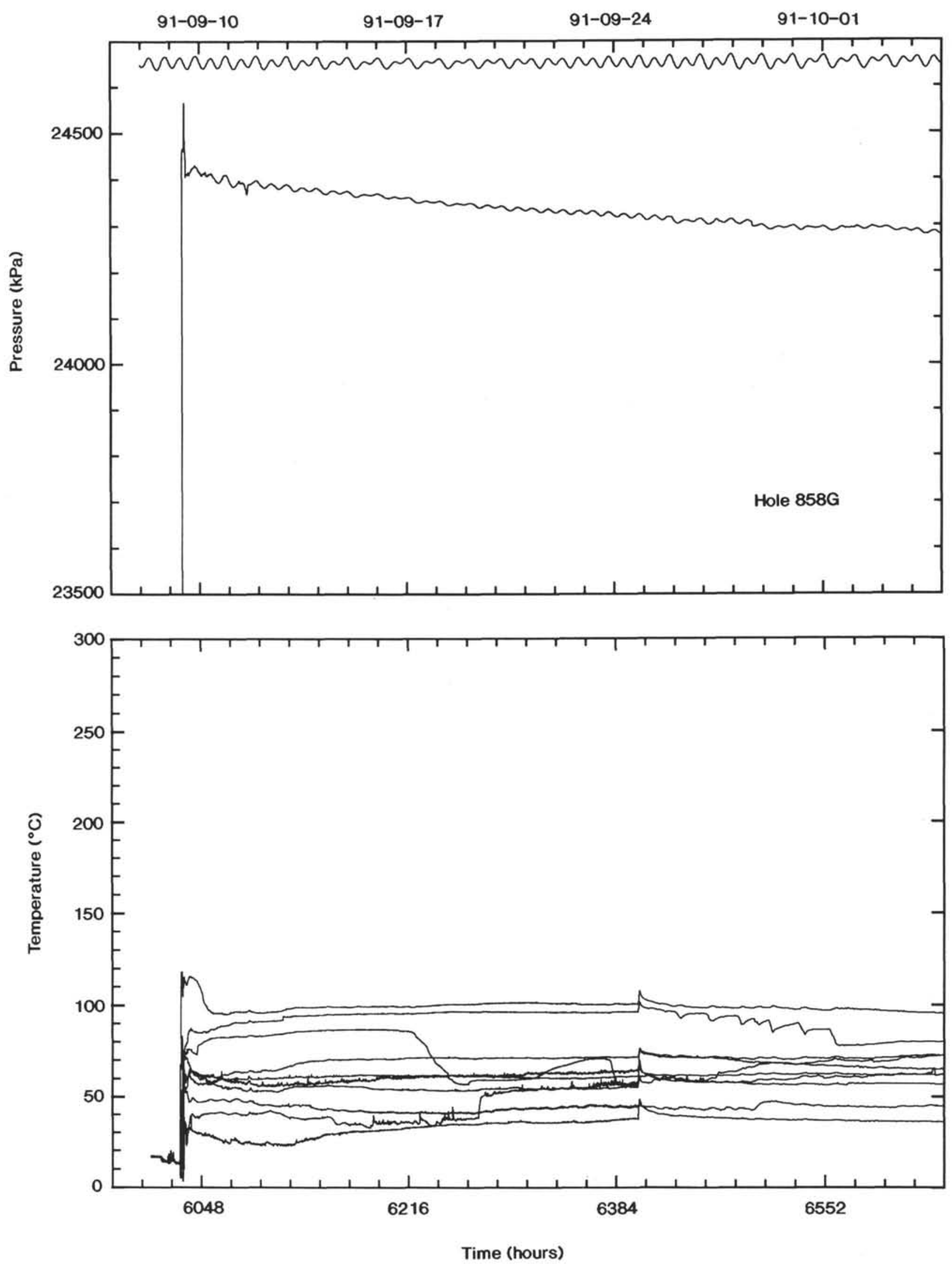

Figure 9. Estimated seafloor pressure (upper line), and measured borehole pressure (lower line) and temperatures (lower plot), recorded during the initial observation period in Hole 858G. Time ticks are given daily and labeled weekly. 
by thermal recovery, but rather to a growing thermal perturbation caused by the continued invasion of cold ocean bottom-water via the nearby exploratory hole. Temperature logs collected during the drilling program showed early signs of invasion of cold water into the upper $150 \mathrm{~m}$ of the formation via the exploratory Hole 858F (Shipboard Scientific Party, 1992b). The CORK temperature data show clearly that this flow extended to a depth at least as great as the deepest thermistor ( $385 \mathrm{mbsf}$ ) at the time of CORK deployment, and that it continued with considerable vigor for a period of two months after Hole $858 \mathrm{G}$ was sealed. This is inferred from the fact that temperatures were relatively cool (less than $100^{\circ} \mathrm{C}$ at all depths, compared to the estimated undisturbed formation temperature of nearly $300^{\circ} \mathrm{C}$ ) and stable for this entire period of time (Figs. 9 and 10).

\section{Overview of the 1-Year Record at Hole 858G}

The full history of temperature and pressure variations recorded in Hole $858 \mathrm{G}$ up to the time of the site visit with the ROV on 3 July 1992 is given in Figure 10. In contrast to the relatively simple histories observed during the first three weeks of recording in both holes, the 10 -month record from Hole $858 \mathrm{G}$ is complex, characterized by large changes that occur both at long (months) and short (less than one hour) time periods, and by large changes in tidal-frequency signals. The records contain far more information than can be analyzed in detail in this preliminary paper. A summary of the data is included in this section, and only semiquantitative discussions and interpretations of a few of the more easily understandable elements of the records are given below.

Pressure in Hole $858 \mathrm{G}$ is seen to have continued to decline for two months following deployment. No change in either temperatures or pressure was observed at the time that Hole $858 \mathrm{~F}$ was plugged, attesting to the inadequacy of the plug in Hole $858 \mathrm{~F}$ as discussed above. This is demonstrated in an expanded view of the pressure record in Figure 11.

While pressure continued to decrease, temperatures in the hole were stable and even increased (e.g., in the latter part of the second month; Fig. 10). This behavior may have been caused by the effects of a finger of cool water from Hole $858 \mathrm{~F}$ sinking below the depth of the hole into the $280^{\circ} \mathrm{C}$ formation. The extent of cool water invasion into the formation can be estimated from the magnitude of the pressure change, roughly $200 \mathrm{kPa}$. To create this change would require a finger of $100^{\circ} \mathrm{C}$ water penetrating roughly $100 \mathrm{~m}$ below the bottom of the hole. Alternatively, the increasingly negative pressure could have been caused by slow sedimentation and restriction of flow through the leaking Hole $858 \mathrm{~F}$, although if this were the case, a significant warming in Hole $858 \mathrm{G}$ would have been expected.

Pressures finally began to rise midway through the third month, but only after the temperatures in the deeper part of the hole began to recover, in part via a sudden large change near the end of the second month of recording (hour 7330; see discussion of "events" below). Temperatures at thermistors $6-10$ had all increased to over $200^{\circ} \mathrm{C}$ midway through the record. Temperatures at thermistors 7 and 8 appear to have recovered to near-undisturbed formation conditions $\left(280^{\circ} \mathrm{C}\right)$ at the end of the recording period. This may be true for thermistors 6, 9, and 10 as well, although this cannot be concluded with certainty. After becoming extremely noisy, thermistor 6 failed completely near hour 12,100 , and thermistors 9 and 10 suffered major offsets near hour 10,000 . Temperatures in the upper part of the hole never recovered, and it is clear that although draw-down in Hole 858F was greatly diminished at the time of the second data recovery, the uppermost $100 \mathrm{~m}$ of the formation was still strongly cooled by continuing downhole flow. The continuing cool conditions in the upper part of the hole may be the cause of the low pressure in the hole that persisted from the time that the temperatures generally stabilized (near the beginning of the sixth month) to the end of the recording period (see discussion of undisturbed formation pressures below). Clearly, this part of the vent field has been left in a highly disturbed state. The observations suggest that if there were hydrothermal vents in the near vicinity, they could have been made inactive. The closest vent, one near Hole $858 \mathrm{~B}$, is only about $60 \mathrm{~m}$ away, although no change in its activity was noted at the time of the second visit of Alvin roughly 1 month into the recording period.

\section{Hydrologic "Events"}

At approximately 2, 4, and 10 months after the beginning of the recording period, the pressure in Hole $858 \mathrm{G}$ dropped suddenly by several tens of kiloPascals (Fig. 12A-C). The decrease during the second of these events (Fig. 12B) was relatively slow, taking place over a period of about 2 days, and was accompanied by a small decrease in temperature throughout the hole. The response of temperature to the pressure change probably reflects the temporary change in the vigor of downhole flow in Hole $858 \mathrm{~F}$ associated with the change in pressure. The cause of this change in pressure is not obvious.

The first and last events (Fig. 12A, -C) are perhaps more easily understood. At the onset of these events (after hour 7330, or on 12 November 1991 between 1000 and 1100 for the first, and after hour 13,057 , or on 28 June 1992 between 0100 and 0200 for the last), pressure decreased very suddenly (in less than the recording interval of 1 $\mathrm{hr}$ ). The change in the first case was about $30 \mathrm{kPa}$, or about $3 \mathrm{~m}$ of head; following the change, the average pressure remained depressed over a period of days. In response to the step-change in pressure, temperatures throughout the hole increased by between $10^{\circ}$ and $50^{\circ} \mathrm{C}$. The changes in temperature were continuous and relatively gradual, with new levels being nearly fully established in 5-10 hr. The change in pressure at the last event was considerably larger, $150 \mathrm{kPa}$, equivalent to $15 \mathrm{~m}$ of head. Following this change, the pressure increased slowly over the last eight days of the recording period. As in the case of the first event, temperatures responded to the step in pressure gradually, with the most rapid changes occurring over periods of 5-10 hr. Temperatures in the bottom of the hole (thermistors 7-10) decreased by $10-20 \mathrm{~K}$ after the event, whereas in the upper part of the hole (thermistors 1-5, with the exception of 2) temperatures increased, by over $100 \mathrm{~K}$ in the case of thermistor 1 . Whether the long-term change in pressure following the event is a simple response to the change in temperature (integrated density) of the fluid in the hole or a true recovery in pressure toward the pre-event level is not clear. The magnitudes of change favor the former explanation.

At this point in our investigation, we can only speculate on the cause of the sudden events. It is clear from the polarity of the relationship between the sudden change in pressure and the subsequent, more gradual change in both temperature and pressure, that the initial changes in pressure are not simply the hydrostatic consequences of changes in temperature (density) in the hole. The sudden changes in pressure must be a result of a hydrologic change in the formation in the vicinity of the hole. Because pressures change in a direction away from inferred formation conditions (see discussion below), it is unlikely that the cause is simply the creation of new permeability and a more effective interconnection between the hole and an undisturbed part of the formation. A true change in formation pressure is implied, possibly associated with tectonic or hydraulic fracturing. Alternatively, the events may be simply the results of sediment caving off the walls and filling the deeper part of Hole $858 \mathrm{~F}$ and increasing the resistance to downhole flow in that open hole. In fact, the characteristics of the last event are remarkably similar to those associated with the initial sealing of the CORK in Hole 857D, which lends support to this explanation. The difference in the longer-term behavior of pressure between the first and last events may be simply the result of the differences in temperature changes that are observed in the hole following the pressure offsets.

\section{Tidal Signals}

Additional information about the formation hydrology at Sites 857 and 858 comes from the variations in pressure and temperature 

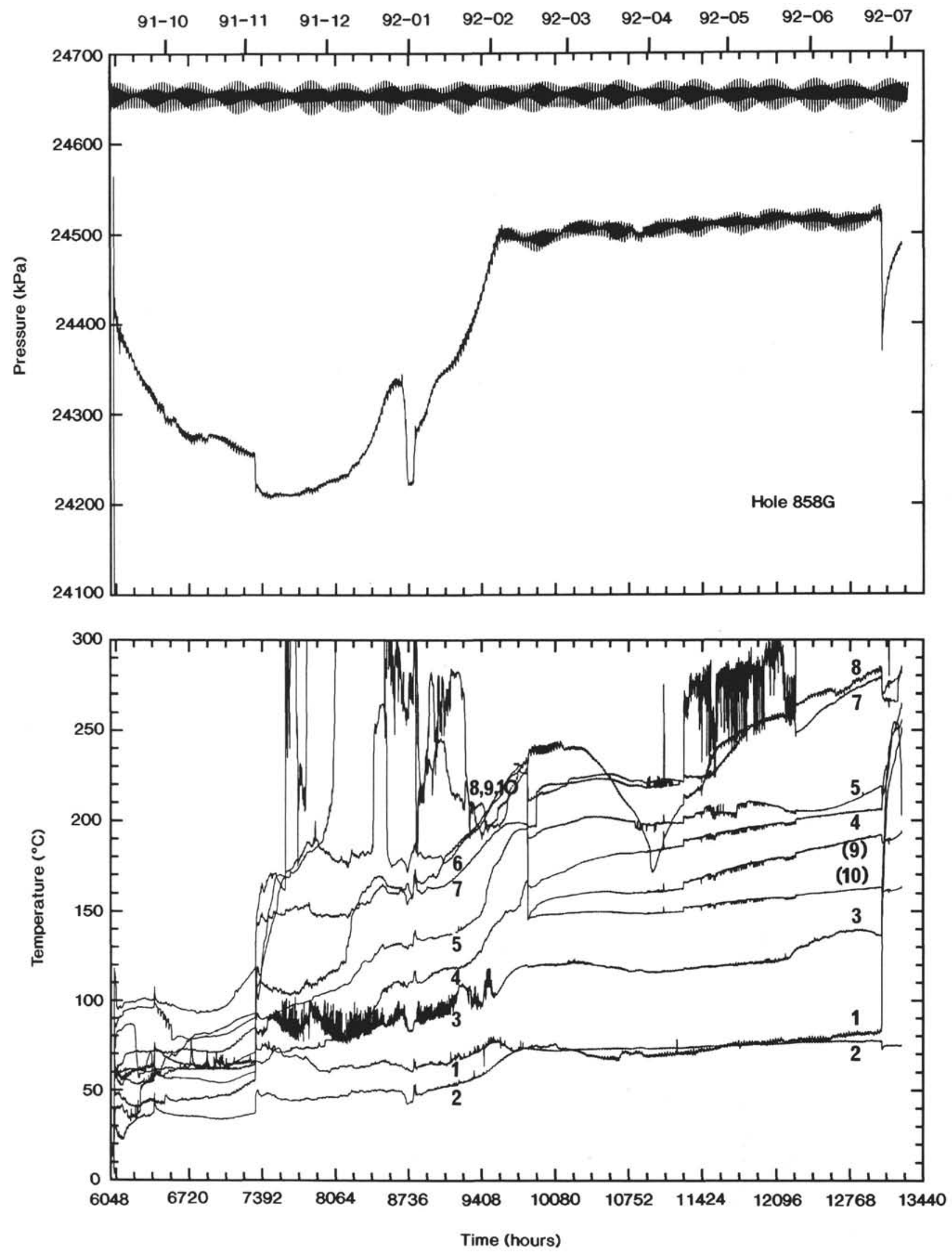

Figure 10. Estimated seafloor pressure (upper line), and measured borehole pressure (lower line) and temperatures (lower plot), recorded over a period of roughly 10 months in Hole 858G. Thermistors are numbered in order along the cable from top (thermistor 1) to bottom (thermistor 10). Time ticks are given weekly and labeled every 4 weeks. Dates are given at the top of the plot for reference. 


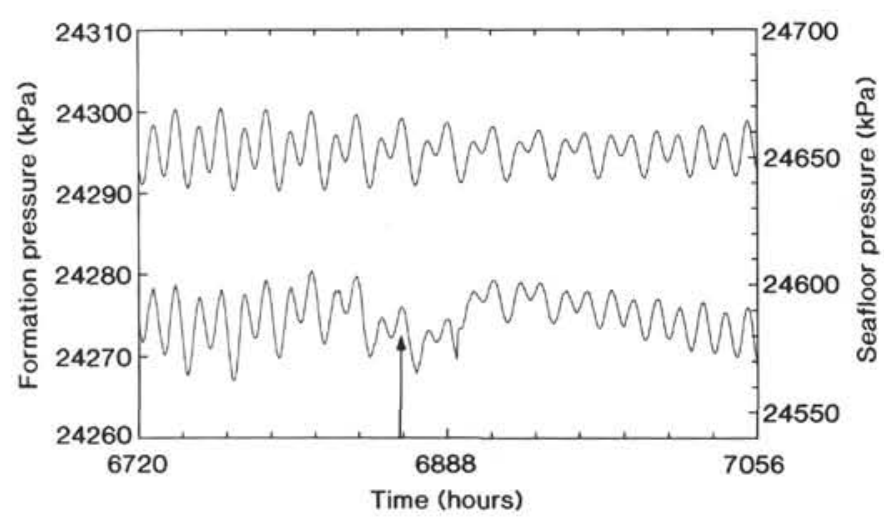

Figure 11. Estimated seafloor pressure (upper line) and measured borehole pressure in Hole 858G (lower line) for the period spanning the time at which the attempt was made to plug the exploratory Hole $858 \mathrm{~F}$ (arrow). Time ticks are given daily and labeled weekly.

at tidal frequencies. Tidal frequency variations in pressure are clearly evident in Figures 8-12; the tidal component, isolated with a low-cut filter, is shown in Figure 13 for a 3-day portion of the early recording period in Holes $857 \mathrm{D}$ and $858 \mathrm{G}$. A comparison of the tidal variations in the holes with those estimated at the seafloor (see discussion above) shows the seafloor tidal "loading" signal to be attenuated differently in each of the holes; the ratio of the formation tide to the seafloor tide is 0.15 in Hole $857 \mathrm{D}$ and 0.45 in Hole $858 \mathrm{G}$. There is no resolvable phase lag of the formation signal relative to the seafloor signal in either hole.

Calculations of signal propagation in a simple semi-infinite compliant permeable medium (van der Kamp and Gale, 1983; Wang and Davis, pers. comm., 1993) suggest that at the depth of our observations, the attenuation is most sensitive to the modulus of the sediment matrix. The formation- to loading-signal amplitude ratio is inversely proportional to the undrained modulus. The zero phase of the signals allows only a crude upper limit to be placed on permeability. Tidal signal characteristics in Hole 857D suggest an undrained modulus for the sediment section of $3.5 \times 10^{10} \mathrm{~Pa}$, and a permeability of less than $4.5 \times 10^{-14} \mathrm{~m}^{2}$ (Wang and Davis, pers. comm., 1993).

The cause of the lesser attenuation (higher amplitude ratio) in Hole $858 \mathrm{G}$ is not clear. One likely possibility is that Hole $858 \mathrm{~F}$ provides a "short circuit" between Hole 858G and the seafloor (Fig. 5), and thus reduces the natural attenuation. Another possibility is that the sediment section at Site 858 is fundamentally different than that at Site 857 . However, lesser attenuation would imply a smaller modulus for the sediment section at Site 858 relative to Site 857 , and this is inconsistent with inferences based on the relatively high degree of induration and high seismic velocities of the sediment at Site 858 (Shipboard Scientific Party, 1992b; Rohr and Gröschel-Becker, this volume).

Additional questions about tidal signal attenuation in Hole $858 \mathrm{G}$ are raised when the full history of the record is examined (Figs. 10 and 14). Large temporal variations in attenuation are apparent, including both gradual and sudden changes. The sudden changes occurred at the times of the events discussed above. The most significant of these changes in attenuation occurred at the last (28 June; hour 13,057) event; the large contrast in the tidal signals before and after this event is shown clearly in Figure 15. The gradual changes occurred over a period of months. The largest attenuation occurred when temperatures in the hole were changing most rapidly, that is, from the time of the event at hour 7330 to the time when temperatures reached a "plateau" at roughly hour 9600 (cf. Figs. 10 and 14). It is interesting that the attenuation during that period and during times following the final event at hour 13,057 reached a value (amplitude ratio $=0.18$ ) close to that observed in the well-behaved Hole 857D (amplitude ratio $=0.15$ ). We suspect that both the sudden and gradual changes in attenuation are associated with physical changes either in the openness of Hole $858 \mathrm{~F}$ or in the efficiency of the interconnection between Holes $858 \mathrm{~F}$ and $858 \mathrm{G}$. Temperatures would recover most rapidly and the influence of a hydraulic "short circuit" would be least when the resistance to flow down the leaking hole is greatest or the permeability of the formation between the holes is least. If Hole $858 \mathrm{~F}$ were to become fully blocked, the attenuation would presumably become roughly equivalent to that in Hole $857 \mathrm{D}$. If the short circuit were highly efficient, the tidal amplitude measured in Hole $858 \mathrm{G}$ would approach the difference between the amplitudes of the seafloor tide and of the natural signal in the permeable basement penetrated by Hole $858 \mathrm{G}$. If the natural signal were the same as that in Hole $857 \mathrm{D}$, the resultant fully short-circuited amplitude ratio would be 0.85 , which is only slightly greater than the largest ratio observed, 0.70 .

This suspected "leaky" behavior is supported by the tidal frequency temperature variations in Hole $858 \mathrm{G}$, which are of greatest amplitude during the period when the tidal pressure signal in the hole is least attenuated. A2-week portion of that part of the record is shown in Figure 16. At all thermistors but one (thermistor 2), temperatures vary inversely with pressure. This suggests that flow into the formation surrounding Hole $858 \mathrm{G}$, via downhole flow of water in Hole $858 \mathrm{~F}$, is modulated by seafloor pressure. Temperature variations are less during other parts of the record in Hole 858G, and no tidal temperature variations are observed in the well-behaved Hole 857D.

The thermal response to pressure during times of low attenuation varies downhole in a fairly systematic way that is understandable in terms of tidally modulated flow into the formation via Hole $858 \mathrm{~F}$, and in terms of the characteristics of the structure and lithology as inferred from observations made during Leg 139 (Fig. 5; Shipboard Scientific Party, 1992b). Temperatures typically vary by a few tenths of a Kelvin and up to $\pm 0.9 \mathrm{~K}$. There is a sharp decrease in amplitude between thermistors 8 and 9 , at the same level that downhole flow into the formation was inferred from shipboard temperature and flow-meter logs (330$340 \mathrm{~m}$; Shipboard Scientific Party, 1992b). This may reflect the continuing effects of the permeability structure on flow. Temperature variations lag slightly behind pressure variations, with lags generally decreasing downhole. This behavior is illustrated in Figure 17, where the tidal pressure and temperature variations are compared directly at six levels in the hole. Temperature lags pressure by roughly 2.2 and 1.5 $\mathrm{hr}$ at thermistors 1 and 2, respectively, which are located in the upper part of the sediment section. Thermistors 5 and 6 are located near the bottom of the sediment section, and still within casing; thermistors 9 and 10 are well below casing in igneous basement. Records for all four of these deeper thermistors are similar, showing time lags of slightly less than one hour. This similarity in the response of thermistors that are inside as well as below casing suggests that effectively none of the thermal lag is due to the transfer of the temperature signal from outside to inside the casing. Convection within the borehole must be sufficiently vigorous to provide efficient thermal coupling between the thermistor cable and the formation outside the casing. Thus, differences in lag in the cased part of the hole must be due to variations in the capacity and permeability of the formation that lies between Holes $858 \mathrm{~F}$ and $858 \mathrm{G}$. Identical lags are expected in the open part of the hole, which creates a low-resistance hydraulic path. That the lag of thermistors in basement is still nearly an hour, and similar to the lag of the thermistors in the deeper part of the sediment section, suggests that the coupling between the bottom of Hole $858 \mathrm{~F}$ in basement and Hole $858 \mathrm{G}$ is no better than that at higher levels within the sediment section. This may be because there is relatively little contrast between the permeability of basement and the permeability of the deeper part of the sediment section (where open fractures may be present; Shipboard Scientific Party, 1992b), or it could be because the deeper part of Hole $858 \mathrm{~F}$ is filled with relatively low-permeability debris (as depicted in Fig. 5; Shipboard Scientific Party, 1992b). Attempts to model this situation, and to derive constraints on the principal hydrologic properties of the section will be made in a future study.

One exception to the systematic behavior described occurs at thermistor 2, where the response of temperature to flow is opposite that 

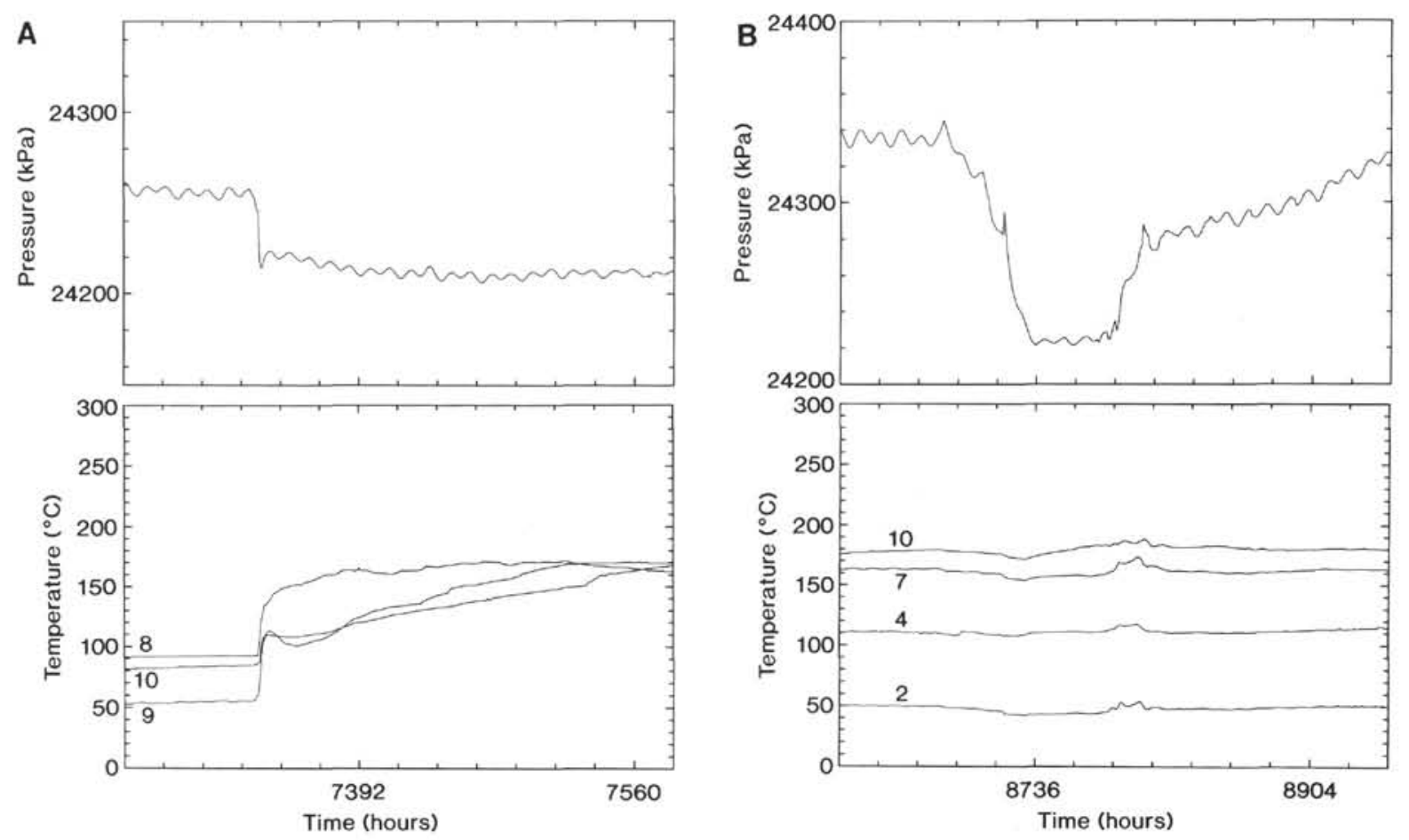

Figure 12. Hole 858G pressure and temperatures at selected thermistors (numbered as in Fig. 10) for times spanning the sudden offsets seen roughly 2 (A), 4 (B), and 10 months $(\mathbf{C})$ from the beginning of the record shown in Figure 10. Time ticks are given daily and labeled weekly.

of the remainder of the hole; temperatures at that level increase with increasing pressure (note inverted scale for thermistor 2 in Fig. 17). This implies that at this level, either warmer water is driven upwards, perhaps along a fracture, during times of increasing pressure, or that the tidally modulated flow occurs in a local interval of inverse thermal gradient (see earlier part of temperature record, Fig. 10).

\section{Estimated Undisturbed Formation Pressures}

One of the primary objectives of the CORK experiment in Middle Valley was to determine the natural formation pressure at two characteristic locations in a sedimented hydrothermal system. Conditions in the permeable basement hydrothermal reservoir are presumably represented at Site 857, and those in a hydrothermal upflow zone beneath a vent field are most certainly represented by Site 858 . Unfortunately, realizing this objective is made difficult by the severity and unknown nature of the thermal perturbation caused by drilling at both sites, which precludes an extrapolation of the seemingly simple pressure recovery curve of Hole $857 \mathrm{D}$, and by the continuing thermal disturbance caused by fluid flow in the leaking Hole $858 \mathrm{~F}$. In addition, the CORK temperature data are flawed, as discussed above, and cannot be relied on for accurate absolute temperatures. To overcome these problems, and to minimize the uncertainties created by the invasion of cool water into the formation below the level of the boreholes, we have adopted a method in which we use the initial shut-in pressure and correct for the anomalous thermal (density) structure of the hole determined as the difference between the estimated formation geotherm and the pre-shut-in temperature log (the term shut-in is used for the time at which the CORKs were latched into the casings).

The method is described through the sequence of Figures 18-21. Figure 18 shows the temperature profiles in the two holes estimated for the undisturbed formation and for the holes at the times of shut-in (Shipboard Scientific Party, 1992a, 1992b; Davis and Wang, this volume). The temperature dependence of density shown in Figure 19 was then used to compute the formation hydrostats shown in Figure 20, and the cold-hole hydrostat that is shown for comparison. Preshut-in openhole hydrostats were also computed but are not shown.
The pressure measured at the time the CORKs were latched reflects a combination of the average natural pressure in the formation below casing, and the effect of the cold, anomalously dense column of water that exists in the hole at the time of shut-in (referred to here as the perturbed hole pressure anomaly). This effect can be quantitatively expressed as the difference between the hydrostat computed using the formation geotherm, and the hydrostat computed using the cooled open-hole temperature profile (Fig. 18). The difference is shown in Figure 21 for each of the two holes. Differences are shown between the estimated formation hydrostats and both cold-hole and pre-shut-in hydrostats, to illustrate that the errors associated with uncertainties in the pre-shut-in temperature profile are small. Also shown in Figure 21 are the pressure differentials across the seals measured at the time the CORKs were latched (Figs. 8 and 9). The comparisons of the measured shut-in differentials and the perturbed hole pressure anomalies provide reasonable constraints on true formation pressures in permeable basement at the two sites, particularly at Site 857 . Problems at Site 858 are discussed below.

In Hole $857 \mathrm{D}$, the shut-in differential matches the level reached by the perturbed hole pressure anomaly at the bottom of the hole (Fig. 21A). We conclude from this that the formation pressure at this site is very close, within a few tens of kiloPascals, to hydrostatic as defined by the local geotherm, and that permeability that is sufficient to leave the dense column of fluid in the hole unsupported persists to the bottom of the hole. All of the over $1 \mathrm{MPa}$ underpressure observed at the time the CORK was latched, at the time of drilling (Shipboard Scientific Party, 1992a), and during post-drilling shipboard packer experiments (Becker et al., this volume) is accounted for by the pressure anomaly created by the cool hole.

In contrast, conditions at Site 858 are not locally hydrostatic. The shut-in differential pressure is about $0.45 \mathrm{MPa}$ greater than the level of the perturbed hole pressure anomaly estimated at the bottom of Hole $858 \mathrm{G}$ (Fig. 21B). We infer from this that although a negative differential of over $0.2 \mathrm{MPa}$ was measured at the time the CORK was latched, in the absence of the drilling disturbance (caused by both Holes $858 \mathrm{~F}$ and $858 \mathrm{G}$ ) basement fluids may be substantially overpressured relative to the hydrostat defined by the local geotherm. 

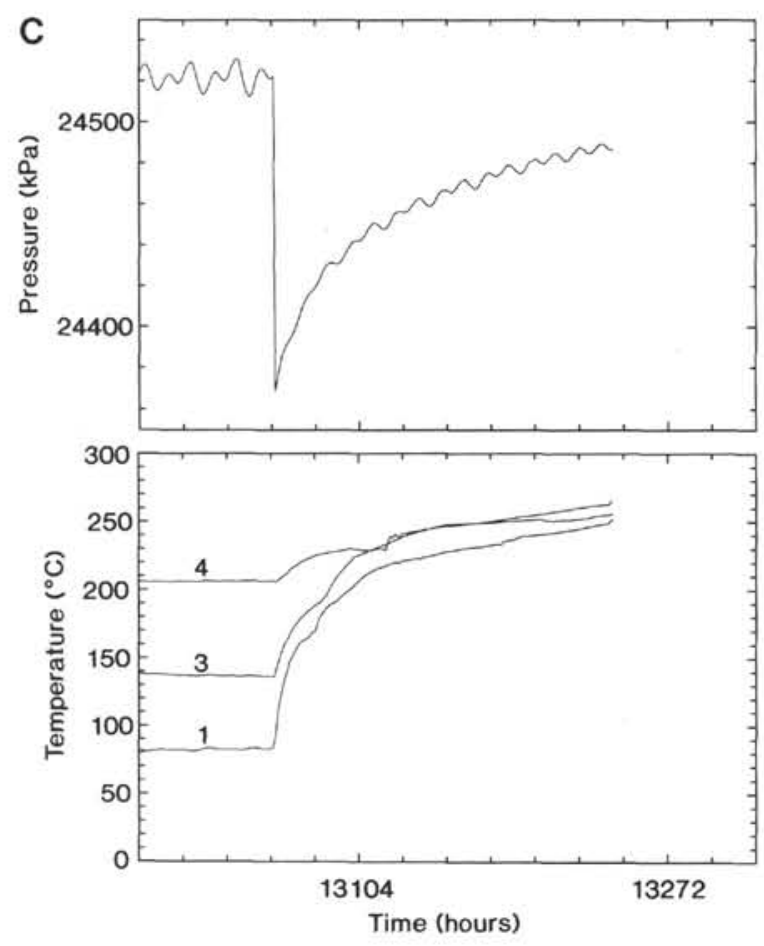

Figure 12 (continued).

The accuracy of this estimate of overpressure is difficult to assess. As discussed above, flow down Hole $858 \mathrm{~F}$ affects temperatures significantly, and the leakage through this hole may directly affect pressure measured in Hole $858 \mathrm{G}$ as well. The size of the effect will depend on the temperature (density) profile of the leaking hole, and on the total pressure drop down Hole $858 \mathrm{~F}$ and through the formation from $858 \mathrm{~F}$ to $858 \mathrm{G}$, relative to the efficiency of the connection of Hole $858 \mathrm{G}$ to the formation into which the open part of that hole penetrates. It can be argued that the effect of leakage through Hole $858 \mathrm{~F}$ should be least when the tidal pressure attenuation is greatest (see discussion above). Using the same method of correcting for the perturbed hole pressure anomaly, but this time with the measured temperatures and pressure in Hole $858 \mathrm{G}$ at the time of greatest tidal signal attenuation (c. hour 7500), results in a formation pressure of $+180 \mathrm{kPa}$. This value of overpressure is less than that estimated using conditions at the time of shut-in, but it is still large. As the effect of the invasion of cool water into the formation below the hole (see discussion above) may have been significant at this time, the value may be considered to be a lower limit for the formation pressure.

\section{An Explanation for the Estimated Borehole and Formation Pressures}

That the estimated fluid pressure in basement at Site 857 is very close to hydrostatic may be a consequence of its being situated fortuitously away from zones of either hydrothermal upwelling or downwelling. Alternatively, the lack of signal may be significant. Numerical simulations of convection in a plane permeable layer capped by sediment (Bessler et al., this volume) suggest that pressure gradients are largest at near-critical conditions; differences in the non-hydrostatic pressure along the top of the permeable basement layer, between locations of upwelling and locations of downwelling, reach values up to $0.25 \mathrm{MPa}$. The differences diminish rapidly, however, with increasing permeability (decreasing resistance to flow). One observation point can be hardly considered representative; nevertheless, to maintain pressure differences of only a few tens of $\mathrm{kPa}$, as suggested by the results presented in Figure 21A, would require the average basement permeability to be higher than about $5 \times 10^{-13} \mathrm{~m}^{2}$. Unfortunately, this conclu-

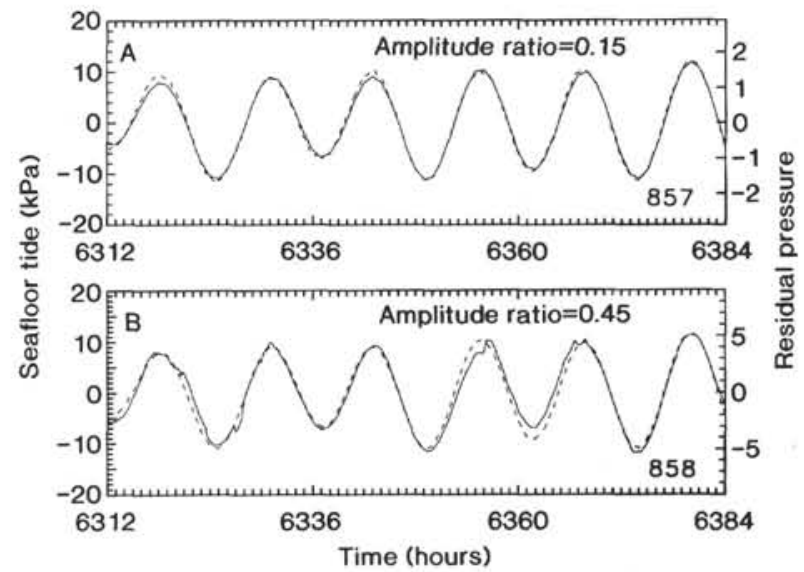

Figure 13. Tidal residuals (solid lines) compared to estimated seafloor tidal pressure variations (dashed lines) for 3 days in an early part of the recording period in Holes 857D (A) and 858G (B). The axes of the residual formation pressure have been expanded by the inverse of the attenuation factors given on the plots. Time ticks are given hourly and labeled daily.

sion is equivocal without knowing just where Site 857 is located with respect to the local convection cells.

The causes and consequences of overpressure in the formation beneath the vent field are explored in Figure 22, where pressure gradients at Sites 857 and 858, derived from the local formation geotherms (Fig. 18), are compared. Site 857 is assumed to be in hydrostatic equilibrium, and the associated pressure-depth profile is plotted with a zero-pressure seafloor intercept. Two extreme profiles of pressures are shown for Site 858 . One is the hydrostat defined by the local estimated geotherm (Fig. 18). The other is identical in local gradient, but the absolute level is shifted by roughly $0.50 \mathrm{MPa}$ to match the pressure at Site 857 at a depth of $470 \mathrm{~m}$, the inferred depth of permeable basement in the region surrounding the high-standing basement structure beneath Site 858 . This assumes that the pressures are closely tied by a high-permeability path in basement. In reality, some pressure must be lost through resistance to flow, so the shifted hydrostat must be considered an upper limit for the pressure in Hole 858G. However, if the corrected pressure of $0.45 \mathrm{MPa}$ calculated above for the time of shut-in is correct, the loss within basement must be small, as this overpressure is close to the total of $0.5 \mathrm{MPa}$ that can be generated by this hot-chimney effect.

The in-situ formation pressure may follow closely the shifted hot hydrostat within the elevated igneous basement edifice beneath Site 858 if the basement permeability is sufficiently high and the rate of fluid flow low. Presumably a great deal of pressure is currently lost within the sediment section along the path of fluid ascent, as there was no evidence for fluid discharge, and thus high pressures, at any time during drilling. Pressures imposed by the cold-hole hydrostat must have been locally equal to or greater than formation pressures. The potential for higher formation pressures within the sediment column are certainly present, however, and we would suggest that the shifted hot hydrostat predicted for conditions in Hole 858G (an artificial high-permeability/low flow path) also provides an upper limit for the formation pressure.

It is interesting that this upper limiting pressure profile intersects a lithostat at a depth of $70 \mathrm{~m}$. This implies that hydrofracturing could occur anywhere above that depth if there were a sufficiently lowresistance path to transmit pressure from basement to a level that high within the sediment section. Observations made during Leg 139 support this conclusion. Brecciation was observed commonly in cores collected from the vent field at Site 858 above a depth of about $50 \mathrm{mbsf}$ (Lithologic Subunit IIB; Shipboard Scientific Party, 1992b), which suggests that occasional superlithostatic pore fluid conditions do occur. In addition, drilling rates increased by a factor of about five below a 

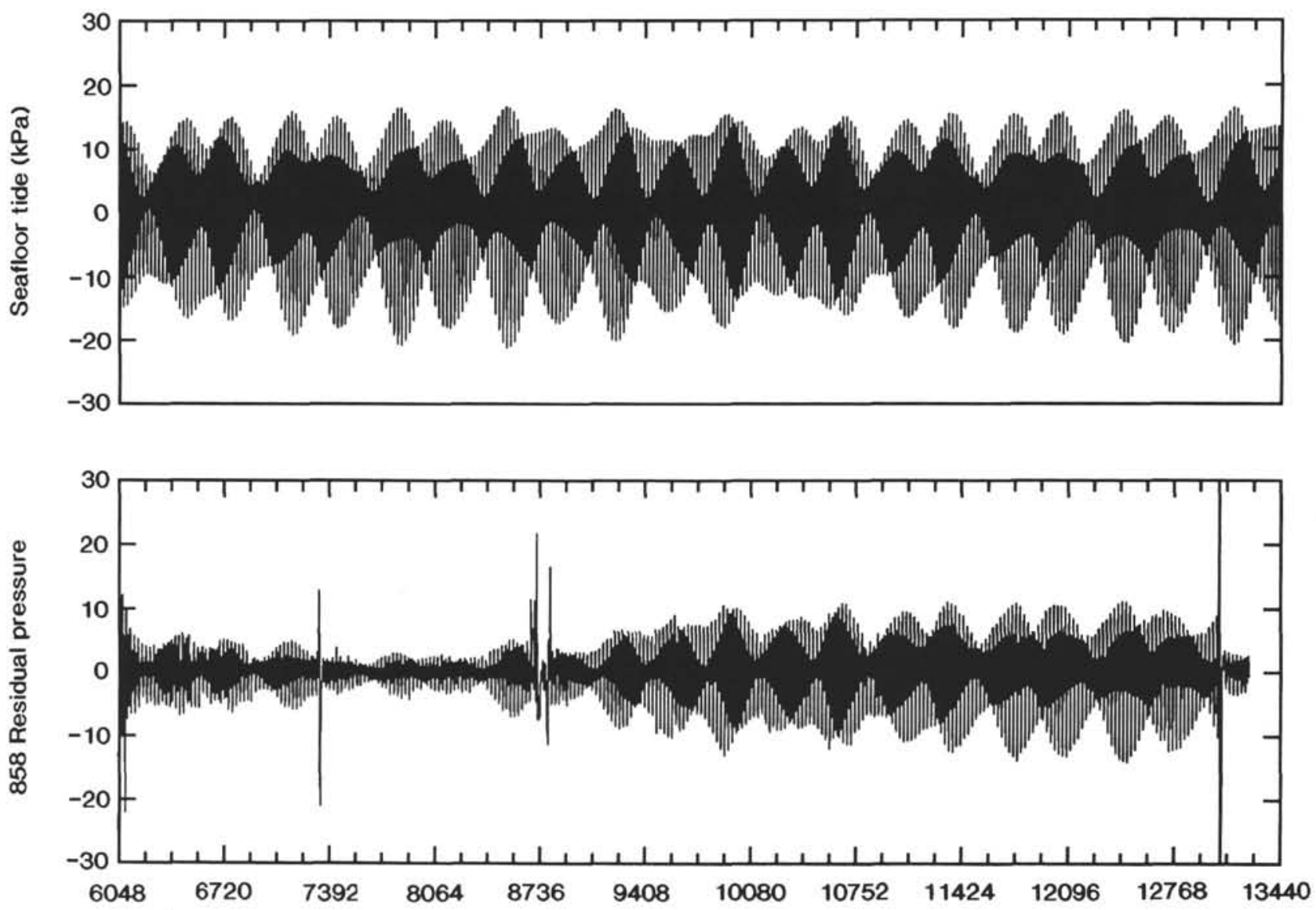

Time (hours)

Figure 14. Hole 858G tidal pressure variations (below) compared to the estimated seafloor tidal variations (above) for the full period of recording. Time ticks are given weekly and labeled every 4 weeks.

depth of about $50 \mathrm{~m}$, perhaps indicating that the section above that depth had been unusually well cemented, possibly as a result of repeated hydrofracturing, brecciation, and mineral precipitation events.

Another consequence of the model developed in Figure 22 is that lateral flow, facilitated by the anisotropic permeability of the layered sediment section, may be driven outward by the higher fluid pressures within the upper part of the basement edifice, and anywhere above that in the high-temperature upflow zone where pressures lie above the 857 hydrostat. A significant pore-fluid compositional anomaly within the sediment section at Site 857, centered close to the depth of the top of the buried basement edifice at Site 858 , is probably the consequence of such flow. High levels of chlorinity, elevated concentrations of calcium and potassium, and depleted concentrations of sodium are similar to those in water that is venting at Site 858 (Shipboard Scientific Party, 1992b). A strong inference can be made that there is a simple hydrologic link, as described above, between the discharge zone at Site 858 and the sediment section at Site $8571.6 \mathrm{~km}$ away.

\section{SUMMARY}

Pressure and temperature data recovered from hydrologically sealed and instrumented Holes $857 \mathrm{D}$ and $858 \mathrm{G}$ provide quantitative information about undisturbed formation conditions in two distinct parts of the hydrothermally active sedimented rift, Middle Valley, visited by Leg 139. Pressures and temperatures were severely affected by the disturbances caused by drilling circulation and the invasion of cool water into permeable parts of the formations penetrated by the holes. Pressure differentials measured across the CORK seals immediately after installation were strongly negative, $-0.24 \mathrm{MPa}$ at $\mathrm{Hole} 858 \mathrm{G}$, and $-1.12 \mathrm{MPa}$ at Hole $857 \mathrm{D}$ (the same as determined during shipboard packer experiments; Becker et al., this volume). All of the negative differential pressure at the latter hole can be accounted for by the effect of the anomalous density of the cool fluid in the hole (referred to as the perturbed hole pressure anomaly), however, and it is concluded that (1) basement is permeable to the bottom of the hole, such that the cold, dense water initially filling the hole is unsupported, and (2) the formation fluid pressure in permeable basement at this site is close to hydrostatic. After accounting for the perturbed hole pressure anomaly in Hole $858 \mathrm{G}$, it is found that fluids in the elevated basement edifice at this site may be overpressured with respect to the estimated local geothermal hydrostat by as much as $0.45 \mathrm{MPa}$. This level of overpressure can be accounted for if (1) the absolute level of pressure in basement were established regionally by the hydrostat in the spatially most representative section (for the purposes of this discussion, the thermally conductive Site 857 ), if (2) basement permeability were high enough to prevent large pressure differentials (see previous discussion and in Bessler et al., this volume), and if (3) the sediment section overlying the basement edifice provided enough hydraulic impedance to "cap" hydrothermal flow. If most of the resistance to flow were near the surface, this would cause a local upflow zone like that at Site 858, where hot, low-density water reaches the surface, to be everywhere overpressured relative to the surroundings. Overpressure in basement beneath Site 858 relative to the surrounding section is supported by evidence for lateral fluid flow in the sediments at Site 857 at the depth of the top of the basement edifice at Site 858. At present, much of the pressure drop between the top of basement and the seafloor is probably distributed throughout the sediment column as fluid ascends to the seafloor above the buried basement edifice. In 

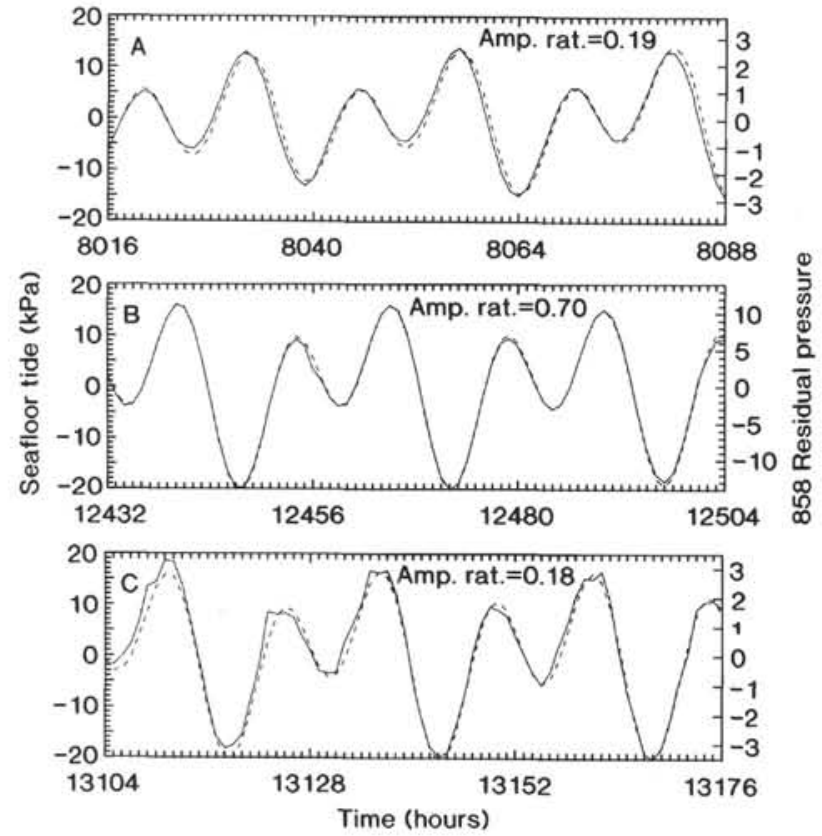

Figure 15. Tidal residuals in Hole $858 \mathrm{G}$ (solid line) and estimated seafloor tidal signals (dashed line) for times during the early period of great tidal signal attenuation (A) (see Figs. 10 and 14), and for times immediately before (B) and after (C) the event roughly 10 months into the recording period (Fig. 12C). Time ticks are given hourly and labeled daily.

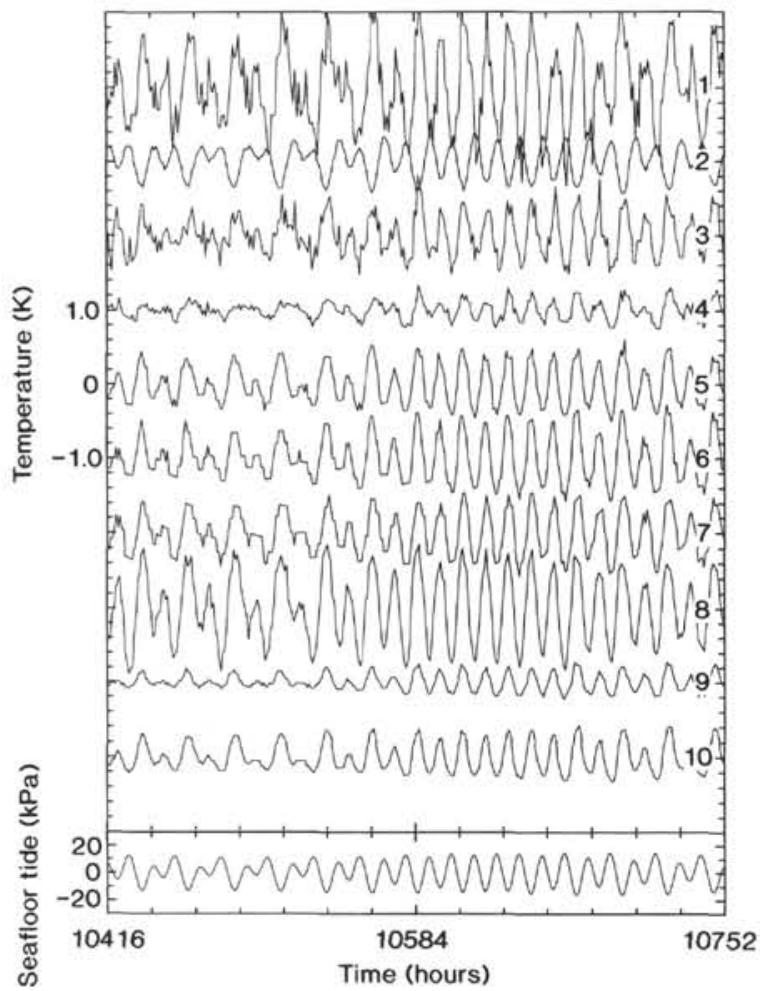

Figure 16. Tidal frequency temperature variations in Hole 858G, showing both negative (most characteristic) and positive (thermistor 2) correlations with tidal pressures. Thermistors, separated by $40 \mathrm{~m}$ and ordered from top to bottom in the hole, are numbered on the plot. Each trace is offset by $1 \mathrm{~K}$ for convenience of display. The estimated seafloor tidal pressure variation is shown at the bottom of the plot. Time ticks are given daily and labeled weekly.

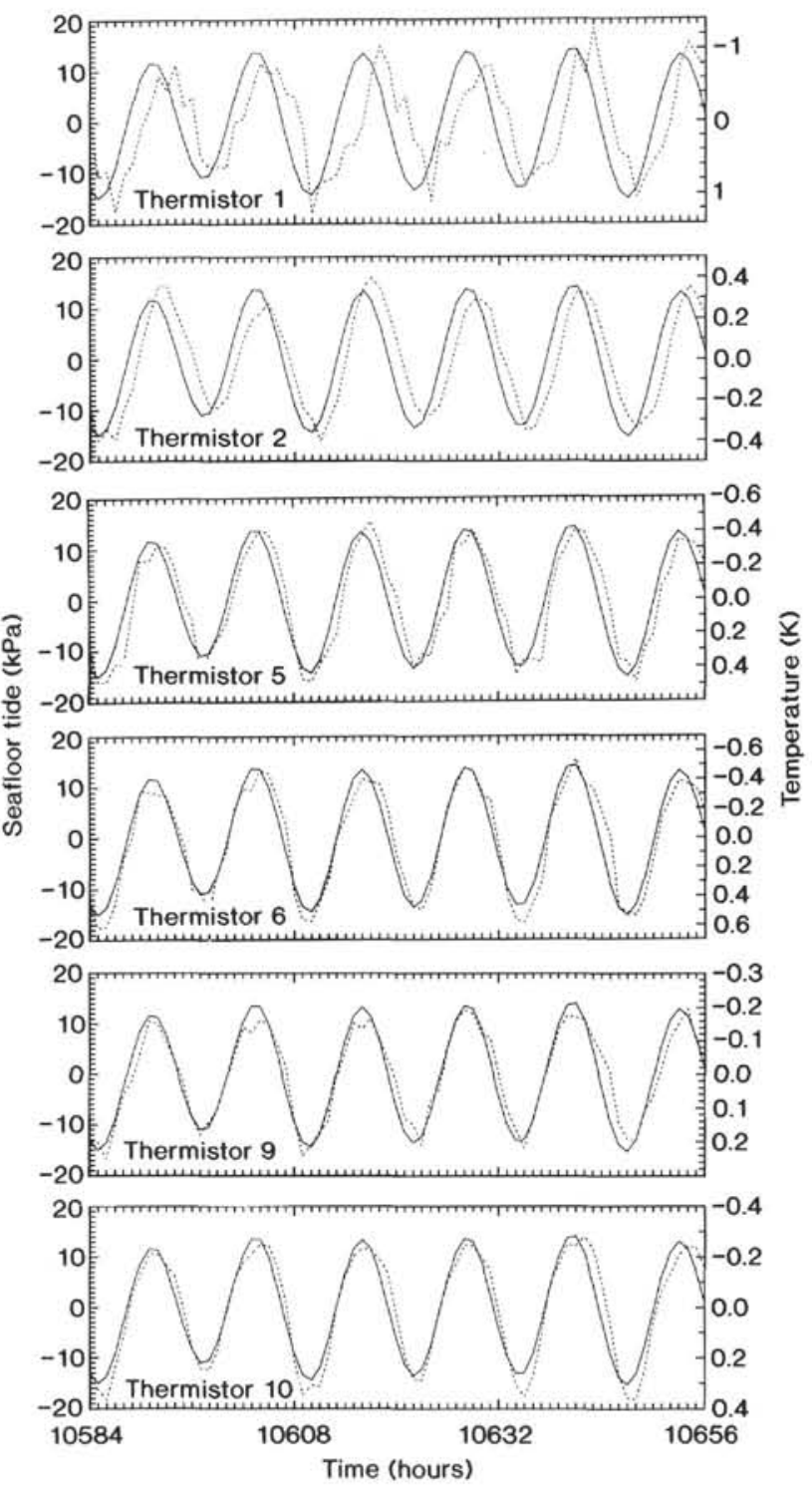

Figure 17. Tidal frequency pressure (solid lines) and temperature (dashed lines) variations in Hole $858 \mathrm{G}$ for thermistors 1 and 2 in the upper part of the sediment section, thermistors 5 and 6 in the deepest part of the sediment section, just above basement and the bottom of casing, and thermistors 9 and 10 within basement, near the bottom of the hole and below casing. Time ticks are given hourly and labeled daily. Note inverted temperature scale for thermistor 2 .

the extreme case (i.e., ascending without loss along a hydrostatic gradient defined by the local hot geotherm that is tied at a depth of $400-500$ mbsf to the regional conductive hydrostat), lithostatic fluid pressures could be reached at a depth of as great as $60-70 \mathrm{~m}$. That overpressures occasionally reach lithostatic is consistent with observations of brecciation of the sediment beneath the vent field at depths as great as 50 mbsf.

During the 3 weeks of recording following the CORK installation in Hole 857D, pressure and temperatures showed clear signs of recovery toward undisturbed conditions. About half of the initial disturbance had dissipated by the end of that period. In contrast, the disturbance in Hole $858 \mathrm{G}$ grew progressively worse for roughly two months as a result of the continuing invasion of cool water into the formation surrounding the hole via the unsuccessfully plugged exploratory Hole $858 \mathrm{~F}$. Although this disturbance appears to have grown progressively weaker during the subsequent 8 months, neither pressure nor temperatures ever reached undisturbed conditions. Clearly, great caution must 

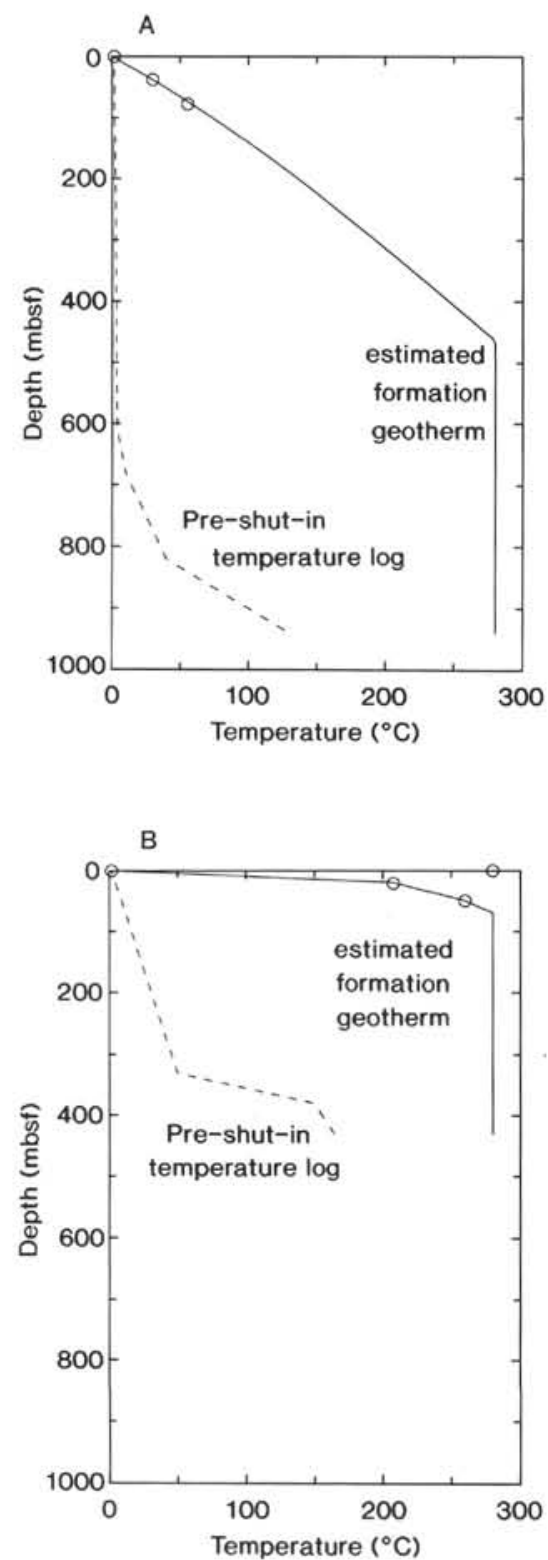

Figure 18. Temperature vs. depth in Hole 857D (A) and Hole 858G (B), estimated for the undisturbed formations at those sites, and for the holes at the times the CORKs were latched into the holes (Shipboard Scientific Party, 1992a, 1992b; Davis and Wang, this volume). Temperatures measured at the seafloor, within the sediment section, and in hydrothermal vents are shown as open circles.

be exercised in the future in siting any open holes where hydrologic disturbances would be unwelcome.

In addition to information provided about undisturbed formation pressures, the CORK data yielded new constraints on the hydrologic properties of the formations drilled. Formation pressure variations resulting from seafloor tidal loading were observed in both holes. The ratio of the formation- to seafloor-tidal signal amplitudes was 0.15 for the 3-week period of recovered data in Hole 857D, and no phase shift was resolvable. The attenuation of the loading signal through the sediment column allows an estimate to be made for the undrained bulk modulus for the sediment section, $3.5 \times 10^{10} \mathrm{~Pa}$; lack of phase puts a crude upper limit on the permeability of the sediment section of $4.5 \times$ $10^{-14} \mathrm{~m}^{2}$. The tidal signal in Hole $858 \mathrm{G}$ was variable and corrupted by the presence of the leaking Hole $858 \mathrm{~F}$; flow of water at a rate sufficient to cause a measurable tidal thermal signal (up to nearly $\pm 1 \mathrm{~K}$ )

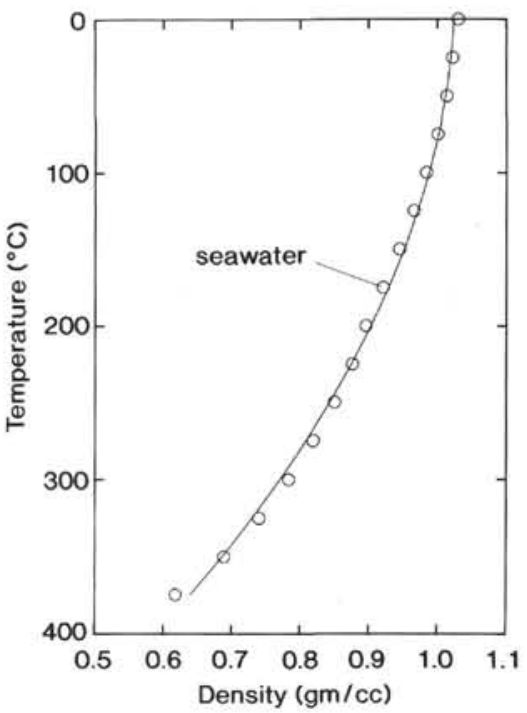

Figure 19. Density vs. temperature for seawater at pressures appropriate for the depth of the Middle Valley rift. Observational constraints (open circles) are from Harr et al. (1984) and Bischoff and Rosenbauer (1985). A quadratic function fitted through the points (solid line) was used to compute hydrostatic pressure profiles (e.g., Figs. $20-22)$, and is given by $\rho=1.024-\left(1.218 \times 10^{-4}\right)$ $\cdot \mathrm{T}-\left(2.411 \times 10^{-6}\right) \cdot \mathrm{T}^{2}$.

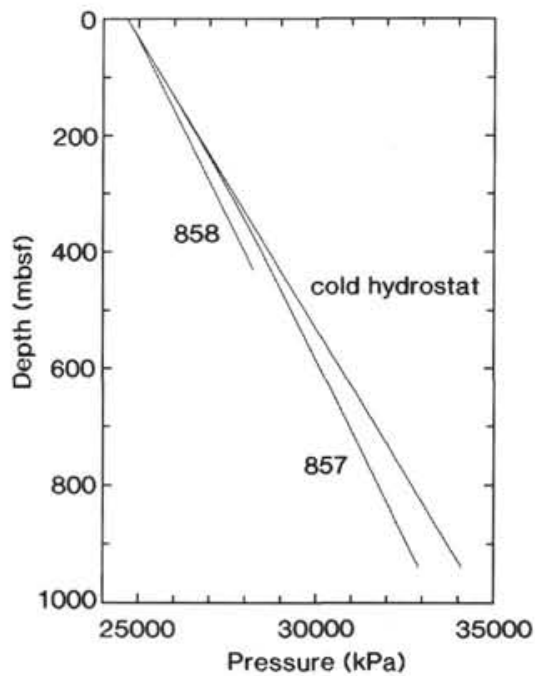

Figure 20. Estimated hydrostats for the formations at Sites 857 and 858 calculated with the temperature-depth profiles shown in Figure 18. A hydrostat for a cold $\left(2^{\circ} \mathrm{C}\right)$ column of seawater is shown for comparison.

was at times driven through the formation by the tidal pressure variations. Variation of the flow and of the attenuation of the tidal pressure signal was probably a result of changes in the degree of interconnectedness between Holes $858 \mathrm{~F}$ and $858 \mathrm{G}$, or a result of variations in the resistance to fluid flow through the open Hole $858 \mathrm{~F}$. The ratio of the attenuated signal to the seafloor tide varied from 0.18 , close to the value observed in the well-behaved Hole $857 \mathrm{D}$, to 0.70 during a time when tidal temperature variations were also most noticeable.

The record of pressure and temperature variations in Hole 858G also included several events. These were characterized by sudden drops in pressure, followed by gradual changes in temperature. Sudden changes in tidal signal attenuation were coincident with the pressure drops. At the time of the largest of these events, the pressure dropped by $150 \mathrm{kPa}$ and the formation tidal signal relative to the sea- 

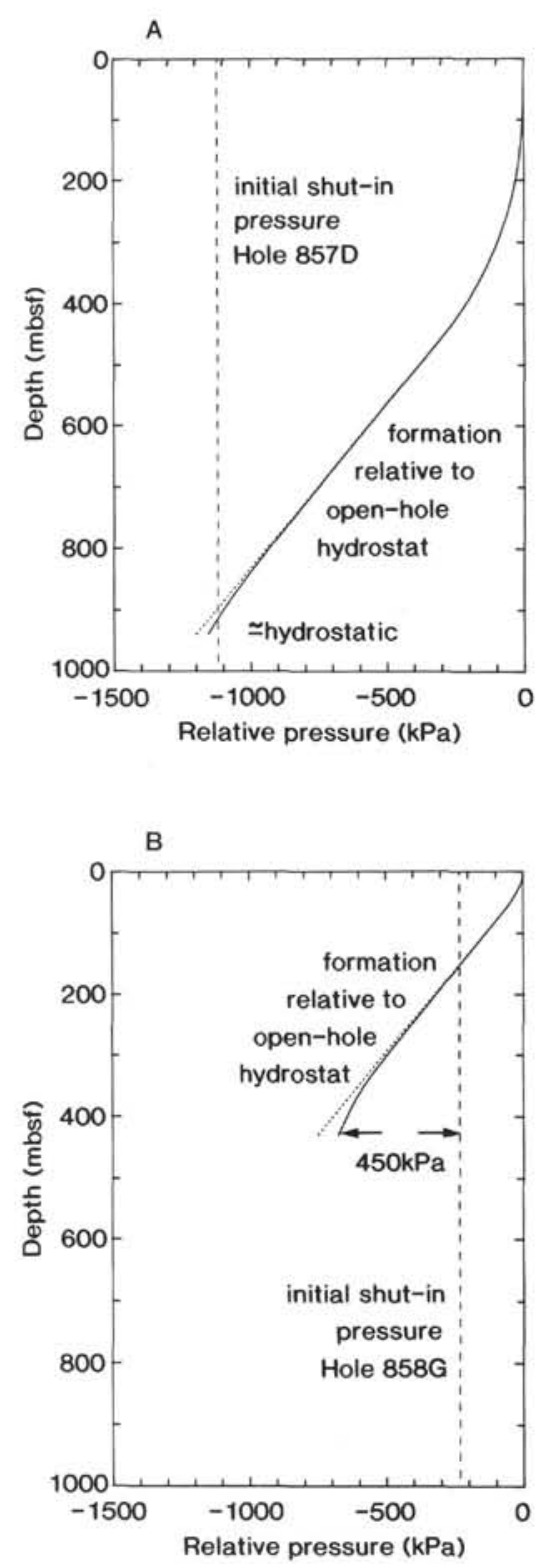

Figure 21. Perturbed hole pressure anomalies (the difference between the hydrostats computed for the undisturbed formation temperature profile and the pre-shut-in temperature profile) for Holes 857D (A) and 858G (B) (solid lines). Dotted lines show the anomalies computed using an isothermally cold $\left(2^{\circ} \mathrm{C}\right)$ temperature profile. Differential pressures measured at the time the CORKs were initially latched in are shown for comparison.

floor tide decreased from 0.70 to 0.18 . Temperatures in the upper part of the section rose by as much as $150 \mathrm{~K}$ within $24 \mathrm{hr}$ of the event. These hydrologic events may have been associated with fracturing events beneath the vent field or in the vicinity of the holes. They could also have been caused by collapse of the walls of Hole $858 \mathrm{~F}$ and partial restriction of draw-down in that open hole.

The next visit to these sites will be made during an Alvin diving program planned for Fall 1993, during which time we will attempt to: (1) recover the full $2 \mathrm{yr}$ of data that we hope will reside in the instrument installed in Hole 857D, which was not visited during the 1992 ROV program, and the additional year of data from Hole $858 \mathrm{G},(2)$ attempt to reposition the plug in the leaking Hole $858 \mathrm{~F}$, (3) replace the logger and short thermistor cable in Hole 857D with a new logger and longer cable so that the observation period can be extended beyond

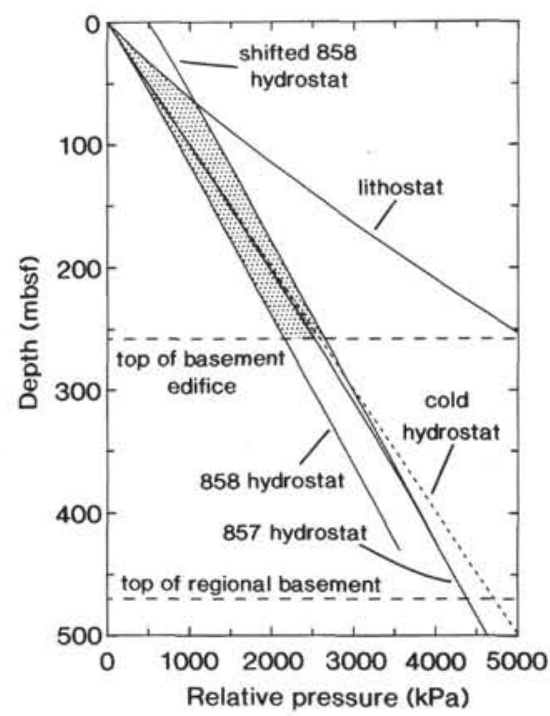

Figure 22. Schematic model for formation fluid pressures beneath the Site 858 Dead Dog hydrothermal vent field, showing the various pressure profiles described in the text. The shifted Site 858 hydrostat is that predicted for equilibrium conditions in the CORKed Hole 858G. The stippled field shows the full range of pressures possible in the sediment section above the basement edifice. The presence of seafloor vents, and venting in Hole 858B (Fig. 1) requires pressures to be substantially above the lower limit of the hydrostat defined by the Site 858 geotherm. The lack of clear signs of discharge during drilling suggests that pressures within the sediment column are currently near or below the cold hydrostat. The estimated pressure of $+0.45 \mathrm{MPa}$ in the cased Hole $858 \mathrm{G}$ suggests that pressures in basement are very close to the shifted Site 858 hydrostat.

the capabilities of the instrument now in place, and so that the spatial and temporal variations in temperature in the permeable part of the section below $450 \mathrm{mbsf}$ can be determined, and (4) install acoustic telemetry modules to allow data to be recovered at future times with a surface ship.

Future modifications to the CORK instrumentation will include the addition of a seafloor pressure transducer to enable the seafloor tidal loading function to be determined without error. We also plan to develop a capability to inexpensively plug, and possibly instrument non-reentry holes. Further work with the existing data will be focused primarily on the analysis of the formation-pressure response to seafloor tidal loading, in order to derive formation-scale mechanical and hydrologic parameters, and to modify and optimize future measurement strategy.

\section{ACKNOWLEDGMENTS}

The authors most gratefully acknowledge the creative and energetic contributions of T. Pettigrew, R. Macdonald, M. Bone, and R. Meldrum to the CORK program. The first data recovery and fluid-port connection operations were made simple by Alvin pilot R. Grieve. The ROV operations were led by K. Shepherd. J. Delaney and R. Embley served as chief scientists during the Alvin and ROV programs. Despite minor problems which we believe have been overcome, the thermistor cables constructed by Cortland Cable Co. have survived well, and the monitoring instruments constructed by Richard Branker Research Ltd. have performed flawlessly. K. Becker was supported through NSF grant no. OCE-9012344. Support for the program has been provided by the Ocean Drilling Program, the National Science Foundation, and the Geological Survey of Canada. Reviews of the manuscript were provided by R. Von Herzen, A. Fisher, and D. Karig. GSC contribution no. 23893. 


\section{REFERENCES}

Alt, J.C., Honnorez, J., Laverne, C., and Emmermann, R., 1986. Hydrothermal alteration of a $1 \mathrm{~km}$ section through the upper oceanic crust, Deep Sea Drilling Project Hole 504B: mineralogy, chemistry, and evolution of seawater-basalt interactions. J. Geophys. Res., 91:10309-10335.

Anderson, R.N., and Zoback, M.D., 1982. Permeability, underpressures, and convection in the oceanic crust near the Costa Rica Rift, eastern equatorial Pacific. J. Geophys. Res., 87:2860-2868.

Anderson, R.N., Zoback, M.D., Hickman, S.H., and Newmark, R.L., 1985. Permeability versus depth in the upper oceanic crust: in situ measurements in DSDP Hole 504B, eastern equatorial Pacific. J. Geophys. Res., 90:3659_ 3669.

Bangs, N.L.B., Westbrook, G.K., Ladd, J.W., and Buhl, P., 1990. Seismic velocities from the Barbados Ridge complex: indicators of high pore fluid pressures in an accretionary complex. J. Geophys. Res., 95:8767-8782.

Becker, K., 1990. Measurements of the permeability of the upper oceanic crust at Hole 395A, ODP Leg 109. In Detrick, R., Honnorez, J., Bryan, W.B., Juteau, T., et al., Proc. ODP, Sci. Results, 106/109: College Station, TX (Ocean Drilling Program), 213-222.

Becker, K., Langseth, M.G., Hyndman, R.D., 1984. Temperature measurements in Hole 395A, Leg 78B. In Hyndman, R.D., and Salisbury, M.H., et al., Init. Repts. DSDP, 78B: Washington (U.S. Govt. Printing Office), 689-698.

Becker, K., Langseth, M.G., Von Herzen, R.P., and Anderson, R.N., 1983. Deep crustal geothermal measurements, Hole 504B, Costa Rica Rift. J. Geophys. Res., 88:3447-3457.

Becker, K., Sakai, H., Adamson, A.C., Alexandrovich, J., Alt, J.C., Anderson, R.N., Bideau, D., Gable, R., Herzig, P.M., Houghton, S., Ishizuka, H., Kawahata, H., Kinoshita, H., Langseth, M.G., Lovell, M.A., Malpas, J., Masuda, H., Merrill, R.B., Morin, R.H., Mottl, M.J., Pariso, J.E., Pezard, P., Phillips, J., Sparks, J., and Uhlig, P., 1989. Drilling deep into the oceanic crust at Hole 504B, Costa Rica Rift. Rev. Geophys., 27:79-102.

Bischoff, J.L., and Rosenbauer, R.J., 1985. An empirical equation of state for hydrothermal seawater (3.2 percent $\mathrm{NaCl}$ ). Am. J. Sci., 285:725-763.

Carson, B., Suess, E., and Strasser, J.C., 1990. Fluid flow and mass flux determinations at vent sites on the Cascadia margin accretionary prism. $J$. Geophys. Res., 95:8891-8898.

Davis, D.M., Suppe, J., and Dahlen, F.A., 1983. Mechanics of fold-and-thrust belts and accretionary wedges. J. Geophys. Res., 88:1153-1172.

Davis, E.E., Becker, K., Pettigrew, T., Carson, B., and MacDonald, R., 1992. CORK: a hydrologic seal and downhole observatory for deep-ocean boreholes. In Davis, E.E., Mottl, M.J., Fisher, A.T., et al., Proc. ODP, Init. Repts., 139: College Station, TX (Ocean Drilling Program), 43-53.

Davis, E.E., Chapman, D.S., Mottl, M.J., Bentkowski, W.J., Dadey, K., Forster, C., Nagihara, S., Rohr, K., Wheat, G., and Whiticar, M., 1992. FlankFlux: an experiment to study the nature of hydrothermal circulation in young oceanic crust. Can. J. Earth Sci., 29:925-952.

Davis, E.E., Goodfellow, W.D., Bornhold, B.D., Adshead, J., Blaise, B., Villinger, H., and Le Cheminant, G.M., 1987. Massive sulfides in a sedimented rift valley, northern Juan de Fuca Ridge. Earth Planet. Sci. Lett., 82:49-61.

Davis, E.E., Horel, G.C., MacDonald, R.D., Villinger, H., Bennett, R.H., and $\mathrm{Li}, \mathrm{H} ., 1991$. Pore pressures and permeabilities measured in marine sediments with a tethered probe. J. Geophys. Res., 96:5975-5984.

Davis, E.E., Mottl, M.J., Fisher, A.T., et al., 1992. Proc. ODP, Init. Repts., 139: College Station, TX (Ocean Drilling Program).

Duennebier, F.K., Stephen, R., Gettrust, J.F., et al., 1987. Init. Repts. DSDP, 88: Washington (U.S. Govt. Printing Office).

Erickson, A.J., Von Herzen, R.P., Sclater, J.P., Girdler, R.W., Marshall, B.V., and Hyndman, R.D., 1975. Geothermal measurements in deep-sea boreholes. J. Geophys. Res., 80:2515-2528.

Gable, R., Morin, R.H., and Becker, K., 1992. Geothermal state of DSDPHoles 333A, 395A and 534A: results from the DIANAUT program. Geophys. Res. Lett., 19:505-508.

Harr, L., Gallagher, J.S., and Kell, G.S., 1984. NBS/NRC steam tables. Hemisphere Publ. Corp.

Hekinian, R., Fevrier, M., Bischoff, J.L., Picot, P., and Shanks, W.C., 1980. Sulfide deposits from the East Pacific Rise near $21^{\circ}$ N. Science, 207:14331444.

Houtz, R., and Ewing, J., 1976. Upper crustal structure as a function of plate age. J. Geophys. Res., 81:2490-2498.

Hyndman, R.D., and Davis, E.E., 1992. A mechanism for the formation of methane hydrate and seafloor bottom simulating reflectors by vertical fluid expulsion. J. Geophys. Res., 97:7025-7041.
Hyndman, R.D., Von Herzen, R.P., Erickson, A.J., and Jolivet, J., 1976. Heat flow measurements in deep crustal holes on the Mid-Atlantic Ridge. $J$. Geophys. Res., 81:4053-4060.

Ingle, J.C., Jr., Suyehiro, K., von Breymann, M.T., et al., 1990. Proc. ODP, Init. Repts., 128: College Station, TX (Ocean Drilling Program).

Judge, A., Duguid, A., Taylor, A., and Allen, V., 1989. The automatic well temperature measuring system installed at Cape Allison C-47 offshore well, Arctic Islands of Canada, Part 1: concept and development. J. Can. Petrol. Tech., 28:89-94.

Koski, R.A., Clague, D.A., and Oudin, E., 1984. Mineralogy and chemistry of massive sulfide deposits from the Juan de Fuca Ridge. Geol. Soc. Am. Bull., 95:930-945.

Langseth, M.G., Mottl, M.J., Hobart, M.A., and Fisher, A., 1988. The distribution of geothermal and geochemical gradients near Site 501/504: implications for hydrothermal circulation in the oceanic crust. In Becker, K. Sakai, H., et al., Proc. ODP, Init. Repts., 111: College Station, TX (Ocean Drilling Program), 23-32.

Lister, C.R.B., 1983. On the intermittency and crystallisation mechanisms of sub-seafloor magma chambers. Geophys. J. R. Astron. Soc., 73:351-366.

Little, S.A., Stolzenbach, K.D., and Von Herzen, R.P., 1987. Measurements of plume flow from a hydrothermal vent field. J. Geophys. Res., 92:25872596.

Menard, H.W., Natland, J.H., Jordan, T.H., Orcutt, J.A., et al., 1987. Init. Repts. DSDP, 91: Washington (U.S. Govt. Printing Office)

Moore, J., Mascle, A., Taylor, E., Andreieff, P., Alvarez, F., Barnes, R., Beck, C., Behrmann, J., Blanc, G., Brown, K., Clark, M., Dolan, J., Fisher, A., Gieskes, J., Hounslow, M., McLellan, P., Moran, K., Ogawa, Y., Sakai, T., Schoonmaker, J., Vrolijk, P., Wilkens, R., and Williams, C., 1988. Tectonics and hydrogeology of the northern Barbados Ridge: results from Ocean Drilling Program Leg 110. Geol. Soc. Am. Bull., 100:1578-1593.

Morin, R.H., Hess, A.E., and Becker, K., 1992. In situ measurements of fluid flow in DSDP Holes 395A and 534A: results from the DIANAUT program. Geophys. Res. Lett., 19:509-512.

Mottl, M.J., and Wheat, C.G., in press. Hydrothermal circulation, Juan de Fuca Ridge eastern flank: factors controlling basement water composition. $J$. Geophys. Res.

Purdy, G.M., 1987. New observations of the shallow seismic structure of young oceanic crust. J. Geophys. Res., 92:9351-9362.

Rona, P.A., Klinkhammer, G., Nelson, T.A., Trefry, J.H., and Elderfield, H., 1986. Black smokers, massive sulfides and vent biota on the Mid-Atlantic Ridge. Nature, 321:33-37.

Schultheiss, P.J., and McPhail, S.D., 1986. Direct indication of pore water advection from pore pressure measurements in Madeira Abyssal Plain sediments. Nature, 320:348-350.

Schultz, A., Delaney, J.R., and McDuff, R.E., 1992. On the partitioning of heat flux between diffuse and point-source seafloor venting. J. Geophys. Res., 97:12299-12314.

Shipboard Scientific Party, 1992a. Site 857. In Davis, E.E., Mottl, M.J., Fisher, A.T., et al., Proc. ODP, Init. Repts., 139: College Station, TX (Ocean Drilling Program), 283-429.

, 1992b. Site 858. In Davis, E.E., Mottl, M.J., Fisher, A.T., et al., Proc. ODP, Init. Repts., 139: College Station, TX (Ocean Drilling Program), 431-569.

Taylor, A., Judge, A., and Allen, V., 1989. The automatic well temperature measuring system installed at Cape Allison C-47 offshore well, Arctic Islands of Canada, Part 2-data retrieval and analysis of the thermal regime. J. Can. Petrol. Tech., 28:95-101.

Van der Kamp, G., and Gale, J.E., 1983. Theory of earth tide and barometric effects in porous formations with compressible grains. Water Resour. J., 19:538-544.

Worthington, P.F., Anderson, R.N., Jarrard, R.D., Becker, K., Bell, J.S., Salisbury, M.H., and Stephen, R.A., 1989. Scientific applications of downhole measurements in the ocean basins. Basin Res., 1:223-236

\footnotetext{
- Abbreviations for names of organizations and publications in ODP reference lists follow the style given in Chemical Abstracts Service Source Index (published by American Chemical Society).
}

Date of initial receipt: 23 February 1993

Date of acceptance: 9 August 1993

Ms 139SR-255 